NBER WORKING PAPER SERIES

\title{
GIFFEN BEHAVIOR: THEORY AND EVIDENCE
}

\author{
Robert T. Jensen \\ Nolan H. Miller \\ Working Paper 13243 \\ http://www.nber.org/papers/w13243
}
NATIONAL BUREAU OF ECONOMIC RESEARCH
1050 Massachusetts Avenue
Cambridge, MA 02138
July 2007

\begin{abstract}
We would like to thank Alberto Abadie, Chris Avery, Sebastian Bauhoff, Amitabh Chandra, Suzanne Cooper, Daniel Hojman, Brian Jacob, Elizabeth Lacey, Erzo Luttmer, Mai Nguyen, Albert Park, Rodrigo Wagner, Sangui Wang, and Richard Zeckhauser for valuable discussions, and Frank Mou, Dulles Wang and Fan Zhang for research assistance. We gratefully acknowledge financial support from the National Institute of Aging, the William F. Milton Fund at Harvard Medical School, the Dean's Research Fund at the John F. Kennedy School of Government, the Center for International Development at Harvard University, and the Hefner China Fund. The views expressed herein are those of the author(s) and do not necessarily reflect the views of the National Bureau of Economic Research.
\end{abstract}

(C) 2007 by Robert T. Jensen and Nolan H. Miller. All rights reserved. Short sections of text, not to exceed two paragraphs, may be quoted without explicit permission provided that full credit, including (C) notice, is given to the source. 
Giffen Behavior: Theory and Evidence

Robert T. Jensen and Nolan H. Miller

NBER Working Paper No. 13243

July 2007, Revised December 2007

JEL No. D01,I30,O12

\section{ABSTRACT}

This paper provides the first real-world evidence of Giffen behavior, i.e., upward sloping demand. Subsidizing the prices of dietary staples for extremely poor households in two provinces of China, we find strong evidence of Giffen behavior for rice in Hunan, and weaker evidence for wheat in Gansu. The data provide new insight into the consumption behavior of the poor, who act as though maximizing utility subject to subsistence concerns, with both demand and calorie elasticities depending significantly, and non-linearly, on the severity of their poverty. Understanding this heterogeneity is important for the effective design of welfare programs for the poor.

Robert T. Jensen

Watson Institute for International Studies

Brown University

Box 1970

Providence, RI 02912

and NBER

Robert_Jensen@harvard.edu

Nolan H. Miller

John F. Kennedy School of Government

Harvard University

79 JFK St

Cambridge, MA 02138

nolan_miller@harvard.edu 


\title{
GIFFEN BEHAVIOR: THEORY AND EVIDENCE *
}

\author{
Robert T. Jensen \\ The Watson Institute for International Studies \\ Brown University \\ and \\ John F. Kennedy School of Government \\ Harvard University \\ and \\ NBER \\ Nolan H. Miller \\ John F. Kennedy School of Government \\ Harvard University
}

December 2007

\begin{abstract}
This paper provides the first real-world evidence of Giffen behavior, i.e., upward sloping demand. Subsidizing the prices of dietary staples for extremely poor households in two provinces of China, we find strong evidence of Giffen behavior for rice in Hunan, and weaker evidence for wheat in Gansu. The data provide new insight into the consumption behavior of the poor, who act as though maximizing utility subject to subsistence concerns, with both demand and calorie elasticities depending significantly, and non-linearly, on the severity of their poverty. Understanding this heterogeneity is important for the effective design of welfare programs for the poor. (JEL D01; I30; O12).
\end{abstract}

KEYWORDS: Giffen Goods; Theory of the Consumer; Consumption; Poverty.

\footnotetext{
* We would like to thank Alberto Abadie, Chris Avery, Sebastian Bauhoff, Amitabh Chandra, Suzanne Cooper, Daniel Hojman, Brian Jacob, Elizabeth Lacey, Erzo Luttmer, Mai Nguyen, Albert Park, Rodrigo Wagner, Sangui Wang, and Richard Zeckhauser for valuable discussions, and Frank Mou, Dulles Wang and Fan Zhang for research assistance. We gratefully acknowledge financial support from the National Institute of Aging, the William F. Milton Fund at Harvard Medical School, the Dean's Research Fund at the John F. Kennedy School of Government, the Center for International Development at Harvard University, and the Hefner China Fund.
} 


\section{INTRODUCTION}

The "Law of Demand," which holds that as the price of a good increases, consumers' demand for that good should decrease, is one of the bedrock principles of microeconomics. However, economists have long recognized that the axioms of consumer theory do not guarantee that demand curves must slope downward, and that the Law of Demand, while descriptively valid in many situations, may not apply to very poor consumers facing subsistence concerns. Alfred Marshall first publicized this idea in the 1895 edition of his Principles of Economics:

As Mr. Giffen has pointed out, a rise in the price of bread makes so large a drain on the resources of the poorer labouring families and raises so much the marginal utility of money to them, that they are forced to curtail their consumption of meat and the more expensive farinaceous foods: and, bread being still the cheapest food which they can get and will take, they consume more, and not less of it. $\quad$ (p. 208)

Since Marshall's time, a discussion of "Giffen" behavior has found its way into virtually every basic economics course despite a lack of real-world evidence supporting Marshall's conjecture. ${ }^{1}$ Studies by Stigler (1947) and Koenker (1977) argue that neither demand for bread nor demand for wheat was upward sloping in Britain during Marshall's time. The standard textbook example of a Giffen good, potatoes during the Irish famine of 1845-1849, has also been discredited (Rosen, 1999). ${ }^{2}$ Not only are there no data to support the claim, but at a more basic level it is unlikely that consumption of potatoes could have increased when the price rose during the famine, at least in the aggregate, precisely because the price rise was caused by a blight that

\footnotetext{
${ }^{1}$ We use the term "Giffen behavior" rather than "Giffen good" to emphasize that the Giffen property is one that holds for particular consumers in a particular situation and therefore depends on, among other things, prices and wealth. Thus, it is not the good that is Giffen, but the consumers' behavior. The Giffen phenomenon should also not be confused with prestige or Veblen goods, where consumers desire the goods precisely because the price is high, "snob appeal," where consumers desire the good because it is rare, or situations where consumers interpret a high price as a signal of high quality. In all three cases, the goods in question are normal. Giffen behavior is a phenomenon that arises entirely within the neoclassical framework where consumers care about price only inasmuch as it affects their budget sets. If demand is Giffen the good in question must also be inferior, which rules out Veblen, snob and signaling effects.

${ }^{2}$ McDonough and Eisenhauer (1995) attribute the potato version of the Giffen story to the 1964 edition of Paul Samuelson's influential textbook (Samuelson, 1964).
} 
destroyed much of the crop. ${ }^{3}$ While there have been some laboratory studies that show evidence of Giffen behavior, these experiments have been far from removed from reality. ${ }^{4}$

In this paper we present data from a field experiment exploring the response of poor households in China to changes in the prices of staple food items that provide the first rigorous, empirical evidence of real-world Giffen behavior. In fact, we find Giffen behavior with respect to two goods, rice and wheat. Further, these goods, and the populations who exhibit Giffen behavior, meet some basic but common conditions that suggest this behavior may be widespread in the developing world. Thus, the absence of previously documented cases most likely results from inadequate data or empirical strategies rather than from their non-existence.

Giffen behavior has long played an important, though controversial, ${ }^{5}$ role in economic pedagogy, as well as in the history of economic thought. However, finding convincing evidence of such behavior is important for economic theory more broadly. The fact that there has to date been no convincing evidence of Giffen behavior stands as a minor embarrassment to economists (Nachbar 1998), one that is reflected in the discussion of the Giffen phenomenon often being presented as a paradox of economic theory rather than as a real (or even possible) mode of behavior (e.g., Stigler, 1947). This lack of evidence has prompted a range of reactions among economists. Some have interpreted it as support for the descriptive validity of the Law of Demand:

Perhaps as persuasive a proof [of the 'Law of Demand'] as is readily summarized is this: if an economist were to demonstrate its failure in a particular market at a particular time, he would be assured of immortality, professionally speaking, and rapid promotion while still alive. Since most economists would not dislike either reward, we may assume that the total absence of exceptions is not from lack of trying to find them.

--George Stigler (1987, p.23).

\footnotetext{
${ }^{3}$ Another argument notes that with upward sloping demand in stable equilibrium (i.e., supply is flatter than demand), the supply reduction due to the famine would actually lower the price of wheat, not raise it. Dwyer and Lindsay (1984) present a summary of the basic case against the potato version of the Giffen paradox. In both the bread and potato cases, it remains entirely possible that poor individuals exhibited Giffen behavior but the market overall did not. However, it is unlikely that the data exist to test this hypothesis.

${ }^{4}$ Battalio et al. (1991) find evidence of upward sloping demand curves among rats given limited "budgets" and the choice between root beer and a quinine solution, and DeGrandpre et al. (1993) find evidence in a laboratory setting that human smokers given the choice between brands of cigarettes and a limited budget of "puffs" can exhibit Giffen behavior.

${ }^{5}$ The lack of verified examples has raised numerous concerns about the pedagogical role of the Giffen story: "Since the Giffen paradox is not useful for understanding the Irish Experience, is it asking too much for future writers of elementary texts to find another example? Fictions have no place in the teaching of economics," Rosen (1999); "We shall have to find a new example of the positively sloping demand curve, or push our discussion of it deeper into footnotes," Stigler (1947).
} 
Others' reactions to the lack of validation for the Giffen phenomenon have been more extreme, interpreting it as an indictment of neoclassical consumer theory. Along these lines, Boland (1977) points out that not only is the theory unable to rule out Giffen behavior, it is also unable to explain why it is not observed. Put another way, if the neoclassical model is correct, then under certain (albeit uncommon) conditions, Giffen behavior should exist. If it has not been observed, it is either because the appropriate conditions have not been satisfied, the appropriate data have not been available to measure it, or the theory is incomplete or flawed. ${ }^{6}$

Beyond documenting the existence of Giffen behavior, our field experiment also provides an opportunity to study more broadly the consumption behavior of the "extreme poor," a population that worldwide includes more than one billion people living below the World Bank's extreme poverty line of one dollar per person per day. These households, like Marshall's "labouring families" and those in our sample, are often highly dependent on a single staple food for the bulk of their nutritional needs. Consequently, such households may be highly vulnerable to fluctuations in the prices of these staple foods, which in effect reduce real wealth and purchasing power. Anecdotally, such price fluctuations, even fairly large ones, are increasingly common in developing countries. ${ }^{7}$ And while there is a large literature examining household vulnerability to income shocks, there is comparably little evidence with respect to price shocks. Our analysis, by focusing on the extremely poor and by introducing exogenous price changes for staple foods, is useful for understanding this vulnerability.

In an earlier (unpublished) version of this paper (Jensen and Miller 2002) using panel data from the China Health and Nutrition Survey, we found suggestive evidence that poor households in China exhibited Giffen behavior with respect to their primary dietary staple (rice in the south, wheat and/or noodles in the north). ${ }^{8}$ However, because the study relied on possibly

\footnotetext{
${ }^{6}$ Others have argued that it is not our understanding of consumers that is flawed, but rather our understanding of markets. For example, Dougan (1982) argues that markets with upward sloping demand curves are inherently unstable, and thus unlikely to be observed, while Nachbar (1998) shows in a general equilibrium framework that observing the equilibrium price and quantity of a good move in the same direction in response to a supply shock implies that the commodity is normal, not inferior, and thus not Giffen at all. Thus economists looking for Giffen behavior at the level of the market are unlikely to find it.

${ }^{7}$ For example, occasional reports from China note rice prices that double from year to year in some localities ("Surge in Consumer Prices Puts China on Guard," China Daily, April 22, 2004). Friedman and Levinsohn (2002) note that the mean price of rice increased by almost 200 percent in Indonesia (where the typical household spends nearly 30 percent of its total household budget on rice) during the 1997/8 financial crisis.

${ }^{8}$ Ours is not the first study to suggest rice as a likely candidate for Giffen behavior. Dwyer and Lindsay (1984) propose (but do not test) this possibility for Singapore, and Chen (1994) finds suggestive evidence of positively sloped demand for rice in Taiwan.
} 
endogenous variation in market prices, we were unable to identify a causal relationship between price changes and consumption. To address this concern, for the present study we conducted a field experiment in which for five months, randomly selected households were given vouchers that subsidized their purchases of their primary dietary staple. Building on the insights of our earlier analysis, we studied two provinces of China: Hunan in the south, where rice is the staple good, and Gansu in the north, where wheat is the staple. Our analysis in these provinces focused on households classified as the "urban poor," a population that includes approximately 90 million individuals throughout China.

Using consumption surveys gathered before, during and after the subsidy was introduced, we find strong evidence that poor households in Hunan exhibit Giffen behavior with respect to rice. That is, lowering the price of rice via the experimental subsidy caused households to reduce their demand for rice, and removing the subsidy had the opposite effect. This finding is robust to a wide range of specifications and methods of parsing the data. In Gansu, the evidence is somewhat weaker, due to the partial failure of two of the basic conditions under which such behavior is expected; namely that the staple good have limited substitution possibilities, and that households are not so poor that they consume only staple foods. Focusing our analysis on those whom the theory identifies as most likely to exhibit Giffen behavior, we find stronger evidence of its existence.

We also provide important new insights into the consumption behavior of poor households. In particular, we find the consumption response to an increase in the price of a staple good follows a previously undocumented inverted-U pattern predicted by consumer theory in the presence of subsistence concerns, with the very poorest and the least poor of the poor responding by decreasing demand in response to an increase in the price of the staple in the standard way, while the group in the middle increases demand (i.e., exhibit Giffen behavior). We also find that households in this middle range, who account for a substantial fraction of the urban poor, actually reduce their caloric intake in response to the price subsidy. Thus, a greater implication of Giffen behavior is the possibility that programs aimed at improving nutrition, whether subsidies, price controls, or indeed almost any other type of program that increases real wealth, may not only be ineffective for this segment of the poor, but can in fact have the exact opposite impact than intended. We argue more broadly that the heterogeneous response of caloric intake 
to price (or wealth) changes has implications for the design, targeting and evaluation of programs designed to improve nutrition.

The paper continues in Section II, where we present a discussion of the consumption behavior of the poor that motivates Giffen behavior. Section III discusses the field experiment, data, and estimation strategy. Section IV presents the results and discusses their implications for policy, and Section V concludes.

\section{GIFFEN BEHAVIOR AND CONSUMPTION AMONG THE POOR}

The conditions under which we would expect Giffen behavior can be demonstrated by elaborating Marshall's statement. ${ }^{9}$ Imagine an impoverished consumer near a subsistence level of nutrition, whose diet consists of only two foods, a "basic" or staple good (in Marshall's case, bread) and a "fancy" good (meat). The basic good offers a high level of calories at low cost, while the fancy good is preferred because of its taste but provides few calories per unit currency. A poor consumer will therefore eat a lot of bread in order to get enough calories to meet his basic needs and use whatever money he has left over to purchase meat. Now, if the price of bread increases, he can no longer afford the original bundle of foods. And if he increases his consumption of meat, he will fall below his required caloric intake. So, he must instead increase his consumption of bread (which is still the cheapest source of calories) and cut back on meat.

The Giffen phenomenon illustrates the potential significance of the wealth effects of price changes for extremely poor households. Although the price increase makes the staple less attractive in relative terms, the fact that it makes the consumer so much poorer (in real terms) forces him to consume more bread. Translating this to the language of consumer theory, the conditions under which Giffen behavior is likely to be observed therefore include that the good in question be strongly inferior and that expenditure on that good comprise a large portion of the consumer's budget. As can be seen from the elasticity version of the Slutsky equation, $\varepsilon_{p}=\varepsilon_{p}{ }^{h}-$ $b \varepsilon_{w}$, where $\varepsilon_{p}$ is the observed price elasticity of demand, $\varepsilon_{p}{ }^{h}(<0)$ is the Hicksian compensated elasticity, $\varepsilon_{w}$ is the wealth elasticity, and $b$ is the budget share of the good, only then can the negative wealth effect of a price increase be large enough to offset the pure substitution effect.

\footnotetext{
${ }^{9}$ Much of the theory of Giffen behavior has previously appeared elsewhere. The interested reader should see the online Appendix to this document for a discussion of the theory underlying this behavior.
} 
In light of these observations, we can state a set of conditions under which Giffen behavior is most likely to be observed: ${ }^{10}$

C1: Households are poor enough that they face subsistence nutrition concerns.

C2: Households consume a very simple diet, including a basic (staple) and a fancy good.

C3: The basic good is the cheapest source of calories available, comprises a large part of the diet/budget, and has no ready substitute.

When dealing with extreme poverty of the sort exhibited by the urban poor in China, another requirement becomes important. While consumers who are too wealthy will not exhibit Giffen behavior, those who are too poor also cannot exhibit Giffen behavior. To take an extreme example, consider a consumer who is so poor that he only consumes bread. When the price of bread increases, he has no choice but to consume less bread. Thus, it is critical to the Giffen story that the consumer be consuming at least some of the fancy goods (e.g., meat) that are more enjoyable but more expensive sources of calories. Otherwise, when the price of the staple increases the consumer cannot increase consumption, since he cannot finance his additional expenditure on the staple by reducing expenditure on some other good. In light of this, we add the following requirement to the three stated above:

C4: Households cannot be so impoverished that they consume only the staple good.

The theory thus predicts that only consumers that are poor, but not too poor, will exhibit Giffen behavior. Panel A of figure 1 depicts the indifference curves for a typical consumer choosing how much of the basic and fancy goods to consume. The basic or staple good is relatively high in calories, while the fancy good offers more "taste," i.e., the enjoyable but nonnutritive aspects of food. ${ }^{11}$ The consumer's indifference map can be divided into three regions. The outer set of indifference curves correspond to the standard case, where the consumer's calorie intake is well above subsistence. Over this range the consumer trades off between calories and taste (and thus between the basic and fancy goods) in an ordinary way. As the consumer's calorie consumption decreases, he crosses into a "subsistence zone." Over this range,

\footnotetext{
${ }^{10}$ Some of these conditions have been noted before by, for example, Gilley and Karels (1991).
} 
caloric intake becomes much more important to the consumer. Consequently, the consumer's indifference curves take on the familiar "elbow" shape associated with Giffen behavior. ${ }^{12}$ Consumers in this range behave as if they maximize taste, subject to the constraint that they meet their minimum caloric needs. As the consumer's calorie consumption decreases even further, he crosses from the subsistence zone to the calorie-deprived zone. In this region, the consumer's calorie intake is below subsistence levels. Hence, his primary concern is maximizing calories, and the consumer's indifference curves are, in effect, iso-calorie curves.
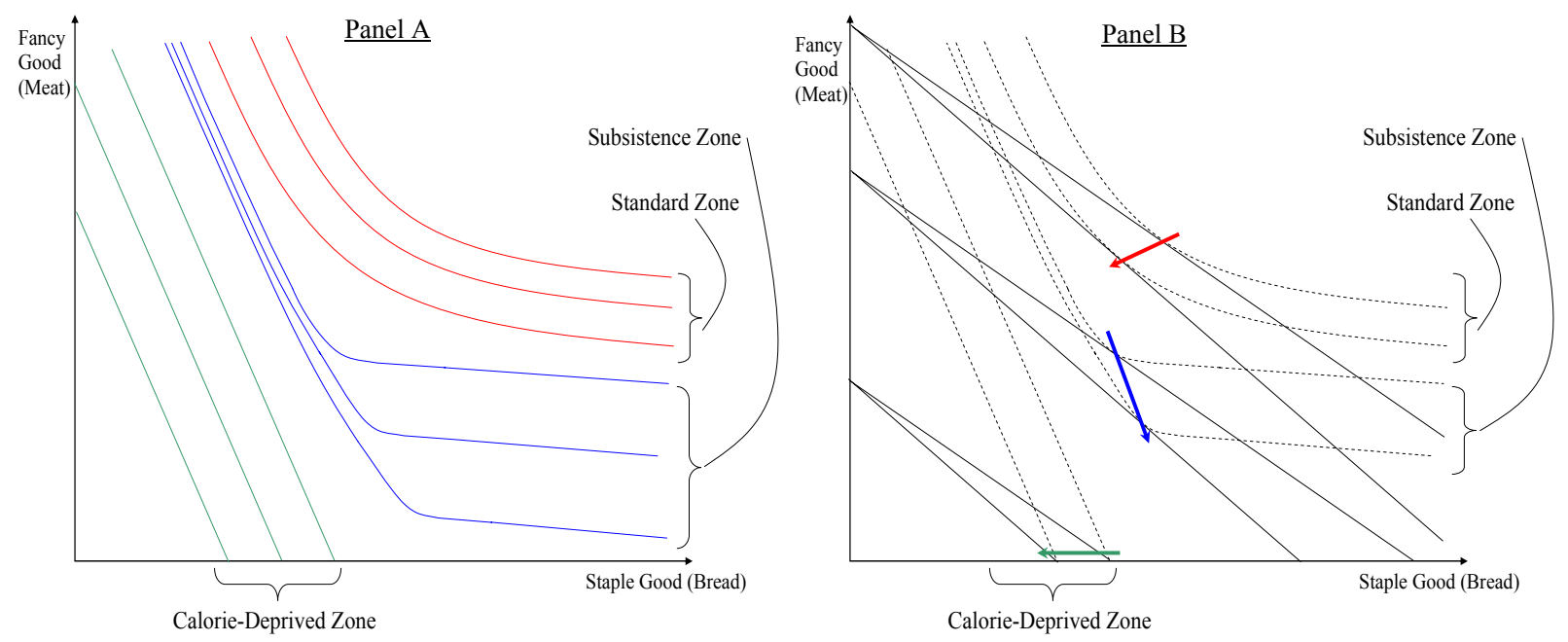

Figure 1. The Zones of Consumer Preferences

The consumer's response to an increase in the price of the staple good will differ across the three regions of his indifference map. When the consumer is relatively wealthy, he will demand a bundle of goods in the standard zone. In this case, as illustrated in panel B of figure 1, we expect the consumer to respond to an increase in the price of the staple good by consuming less of it. Thus, demand is downward sloping. As wealth decreases, the consumer's demand moves into the subsistence zone, and the consumer focuses more on maintaining caloric intake as his primary goal. It is over this region that Giffen behavior arises, as the consumer responds to an increase in the price of the staple good by substituting toward the cheaper source of calories, which is still the staple good. Over this range, the consumer still trades off calories against taste, although caloric intake is given much greater importance. A consumer in the subsistence zone

\footnotetext{
11 The potential substitution across goods with varying nutritional and non-nutritional attributes also motivates the large literature concerned with the income elasticity of demand for calories (see Strauss and Thomas 1995 and Deaton 1997 for surveys). We discuss the relevance of our results to this literature in section IV.F.

${ }^{12}$ See the online Appendix for more discussion of the relationship between the shape of indifference curves needed to generate Giffen behavior and subsistence concerns.
} 
behaves, in effect, as if he maximizes taste subject to the constraint that calories reach a certain minimum requirement. Finally, as the consumer's wealth decreases even further, he is unable to afford to meet his subsistence calorie needs. Calories are maximized by consuming only the staple good, and so the consumer has no choice but to respond to an increase in the price of the staple good by consuming less of it.

This set of predictions provides important insight into the search for Giffen behavior and may also help explain why such behavior has not been previously detected. First, we should not expect to observe Giffen behavior at the market level; a subset of consumers might exhibit Giffen behavior with respect to a particular commodity while the overall market exhibits downward sloping demand. Thus, the search should not be for a "Giffen Good," but for Giffen behavior. In addition, the non-linear response suggests the search is even more nuanced than just focusing on the poorest households. Selecting just the very poorest, or even aggregating over a broader set of households that includes both those in the calorie-deprived and subsistence zones, may not be sufficient. Consumers in the intermediate, subsistence range must be isolated in order to find such behavior.

\section{EMPIRICAL STRATEGY}

\section{A. The Experiment}

A central problem in documenting Giffen behavior, and indeed in any analysis of demand, is finding both sufficient and exogenous price variation. As a practical problem, whether data are cross-sectional, time-series or panel, there is often not a great deal of variation in prices for the kinds of goods likely to be candidates for Giffen behavior. This applies especially to cross-sectional data, as arbitrage should eliminate spatial price differences, especially for easily storable and non-perishable commodities such as grains. Further, the prices for staple goods might even be fixed by the government for the poorest households, such as under India's Public Distribution System, and any remaining price variation may be due to unobservable quality differences. A more serious concern is that even with sufficient price variation, the source of that variation is often potentially endogenous, since price is the equilibrium of a system of simultaneous equations. A positive correlation between price and consumption could simply represent shocks to, or differences in, demand over space or time; higher demand leads to higher prices, which could be misinterpreted as Giffen behavior. 
Although instrumental variables could address this problem, finding instruments that shift supply but do not directly affect demand is difficult. ${ }^{13}$

To overcome these challenges, we conducted a field experiment in which we provided randomly selected poor households in two Chinese provinces with price subsidies for staple foods. In Hunan, a southern province, rice is the staple good, and in Gansu, a northwestern province, wheat is the staple good (consumed primarily as buns, a simple bread called mo or noodles). These regional differences in preferences are primarily determined by geography, climate and history, with wheat the dominant crop grown in Gansu and rice dominant in Hunan. Accordingly, we subsidized rice (only) in Hunan and wheat flour (only) in Gansu.

Within each sample cluster (described below), households were randomly assigned to either a control group or one of three treatment groups. Households in the treatment groups were given printed vouchers entitling them to a price reduction of $0.10,0.20$ or 0.30 yuan $(\mathrm{Rmb} ; 1$ $\mathrm{Rmb} \approx \$ 0.13)$ off the price of each jin $(1$ jin $=500 \mathrm{~g})$ of the staple good (the subsidy level stayed fixed for each household over the course of the study). These subsidies represented substantial price changes, since the average pre-intervention price of rice in Hunan was 1.2 yuan/jin, and the average for wheat flour in Gansu was 1.04 yuan/jin. The vouchers were printed in quantities of 1 , 5 and $10 \mathrm{jin}$, and the month's supply of vouchers was distributed at the start of each month, with each household receiving vouchers for $750 \mathrm{~g}$ per person per day (about twice the average per capita consumption). All vouchers remained valid until the end of the intervention. Households were told in advance they would receive vouchers for five months and that any un-redeemed vouchers would not be honored afterwards.

The vouchers could be redeemed at local grain shops. The merchants in these shops agreed to honor the vouchers in exchange for reimbursement and a payment for their participation. Households and merchants were told they were not permitted to exchange the

\footnotetext{
${ }^{13}$ Most previous studies of Giffen behavior have failed to address this identification concern. A few cases have used instrumental variables, but with problematic instruments. For example, Bopp (1983) uses refinery utilization rates and the price of crude oil as instruments for the price of kerosene; however, both instruments likely also affect the price of substitute fuels, and are likely to be driven by other unobserved factors also affecting fuel demand, such as weather. Baruch and Kannai (2001) use the lagged prime interest rate as an instrument for the price of a low-grade Japanese alcohol (shochu), which is likely be a poor predictor of the price of shochu, or, to the extent that it does predict the price, will likely also affect the prices of substitutes (or income - and thus demand). Rainfall is commonly suggested as an instrument for price. However, rainfall will be an invalid instrument for the price of a given food item since it likely also affects the prices of other foods, as well as wages and income. One exception to the endogeneity concern in the search for Giffen behavior is McKenzie (2002), who uses the elimination of tortilla subsidies and price controls as a natural experiment to test for (and ultimately reject) such behavior in Mexico.
} 
vouchers for anything but the staple good, that there would be periodic auditing and accounting to make sure they were in compliance with the rules, and that any violations would result in them being removed from the study without any additional compensation. Households and merchants were explicitly told that selling the vouchers for cash or reselling rice or wheat bought with the vouchers would result in dismissal from the program.

There are several points about the intervention worth noting. First, all foods in China are sold in free markets, at market determined prices. A 1993 reform of the grain distribution system largely put an end to price controls, state food stores, or free rations. Second, the number of subsidized households in each sample site is trivial relative to the size of the population (all sites were county seats, most with populations over one million), so the intervention could not have affected market prices. ${ }^{14}$ Third, the experiment is predicated on the assumption that either households are limited in their ability to borrow and save, or they have short planning horizons; otherwise, the wealth effect of the five-month subsidy would be trivial, making Giffen behavior unlikely. Although, to the extent the wealth effect of the price change can be smoothed over the lifetime, this will bias us against finding Giffen behavior. Fourth, limiting the quantity of vouchers to $750 \mathrm{~g} /$ person/day might limit the potential demand response for the staple good (though the amount is still quite generous), but it should not induce Giffen behavior, as might be the case (though still unlikely) if we limited the vouchers to a quantity smaller than what they would prefer to consume. ${ }^{15}$ Finally, while staple foods such as rice can be found in varying qualities or varieties with different prices, because the households in our sample are extremely poor, our data show that they consume almost exclusively only the lowest-cost variety. Therefore, quality substitution in response to the price subsidy is not a concern for our analysis. Two final concerns with the experiment, namely whether there was cheating (in the form of cashing out or reselling) despite our rules against doing so or whether the vouchers might create a "salience" or signaling effect, are discussed with the results in section IV.E.

\section{B. Data}

\footnotetext{
${ }^{14}$ Similarly, because the samples were drawn from lists of the poor spread throughout large cities, we believe it is unlikely the various study participants knew each other or the benefits others were receiving.

${ }^{15}$ One concern is that by limiting the potential increase in consumption in response to the price decline, we might skew the average consumption change towards a decline (i.e., Giffen behavior). However, in practice almost no households even approached the voucher limit, most likely due to their extremely low incomes and a lack of access to credit, so this is unlikely to be a major concern.
} 
The survey and intervention were conducted by employees of the provincial level agencies of the Chinese National Bureau of Statistics. The sample consisted of 100-150 households in each of 11 county seats spread over Hunan and Gansu Provinces (Anren, Baoqing, Longshan, Pingjiang, Shimen and Taojiang in Hunan, and Anding, Ganzhou, Kongdong, Qingzhou and Yuzhong in Gansu), for a total of 1,300 households (650 in each province), with 3,661 individuals. Within each county, households were chosen at random from lists of the "urban poor" maintained by the local offices of the Ministry of Civil Affairs. ${ }^{16}$ Households on this list fall below a locally-defined poverty threshold (the Di Bao line), typically between 100 and 200 yuan per person per month or $\$ 0.41-\$ 0.82$ per person per day, which is below even the World Bank's extreme poverty line of one dollar per person per day. It is estimated that about 90 million individuals throughout China live below the Di Bao threshold (Ravallion 2007).

The questionnaire consisted of a standard income and expenditure survey, gathering information on the demographic characteristics of household members as well as data on employment, income, asset ownership and expenditures. A key component of the survey was a 24-hour food recall diary completed by each household member. Respondents were asked to report everything they ate and drank the previous day, whether inside or outside the home, by specifically listing the components of all foods eaten. ${ }^{17}$ These foods were recorded in detail in order to match with the 636 detailed food items listed in the 1991 Food Composition Tables constructed by the Institute of Nutrition and Food Hygiene at the Chinese Academy of Preventative Medicine. Though as we will see below, because households are very poor, most diets are very simple and consist of a small number of basic (non -processed, -prepared or packaged) foods like rice, bean curd or stir-fried cabbage, so concerns about coding the specific quantities of the various ingredients in a complex dish or meal are not significant. ${ }^{18}$

Data were gathered in three waves, conducted in April, September and December of 2006. After completing the first survey, treatment households were told they would receive the

\footnotetext{
${ }^{16}$ We chose urban areas because in smaller towns or rural areas many of the poorest households grew rather than purchased their staple food, and lower population density meant fewer households living in extreme poverty, which would have both required a greater number of sample clusters and prevented varying the treatment within clusters.

${ }^{17}$ While it may seem difficult to recall or estimate how many grams of, say, rice was eaten with a meal, for the extreme poor who are on a very limited budget, food is often apportioned and accounted for much more carefully. Further, diets for these extremely poor households often vary little or not at all from day-to-day, except on special occasions, so recalling the quantity of specific food items is not as difficult.

${ }_{18}$ Similarly, because households were so poor, almost all food (98 percent) was at-home consumption, so respondents were aware of the exact ingredients and quantities used.
} 
subsidies for five months, from June through October. Thus, the initial interviews occurred before treatment households knew of or received the subsidies, the second occurred after the subsidy had been in place for slightly more than 3 months, and the final interviews were conducted 1 to 2 months after the subsidy had ended, by which time treatment households would likely have exhausted any stocks of rice or wheat flour they may have purchased with the subsidy, and will therefore again be purchasing at the full market price. Sample attrition was extremely low, since the three rounds occurred in a relatively short span. Only 11 of 1,300 households $(<1 \%)$ in the first round did not appear in the second round. All households in the second round were interviewed in the third round. Means and standard deviations for key variables are presented in table $1 .^{19}$

Table 2 shows the basic characteristics and prices of foods in Hunan and Gansu. The data are for the most commonly consumed, representative foods within a category; ${ }^{20}$ information on calories and protein are obtained by merging with the 1991 Food Composition Tables. The table shows that, consistent with their respective roles as staple foods, the cheapest source of calories in Hunan is rice (1399 calories per yuan), while in Gansu it is wheat (1655 calories per yuan). These foods are cheaper sources of calories than even the least expensive alternative grain, millet. By contrast, if we view fat as a crude measure of taste, pork provides the most taste per yuan. While rice and wheat appear to be inexpensive sources of protein as well, these nutritional data are somewhat misleading; lacking a few essential amino acids, these grains only provide protein when combined with the amino acids found in other foods, such as pulses (and vice-versa for pulses, which do not provide complete proteins unless combined with grains). Given that households are already consuming a large amount of rice or wheat, pulses are a less expensive source of protein than pork. However, they provide significantly less fat or taste per yuan. Finally, cabbage is the least expensive food per kilogram in both provinces, but it provides very few calories (or amino acids for creating protein), and thus is not a substitute for rice or wheat.

Table 3 shows the basic consumption patterns for households in the two provinces. The dominance of (and difference in) staple goods in the two regions is evident. In Hunan, the

\footnotetext{
${ }^{19}$ While there are some differences in variables across control and treatment groups, these arise largely due to random variation given the relatively small sample size. Randomization was done blindly by the authors, rather than the field teams, so any differences should not be systematic. Further, any differences in variables across households based on treatment assignment will be eliminated because our analysis uses household fixed effects.

${ }^{20}$ Rice: late, long-grain (wanxian); wheat: standard (Biaozhunfen); bean curd (nandoufu); cabbage (Dabaicai (xiaobaikou)); pork: lean and fatty (Zhurou (feishou)); Millet: foxtail (xioami); eggs: hen eggs (jidan).
} 
average per capita consumption of rice per day is $330 \mathrm{~g}$, comprising 64 percent of daily caloric intake. The dominance of rice consumption is widespread in Hunan; the $25^{\text {th }}$ percentile of the distribution of rice calorie share is 52 percent, the $75^{\text {th }}$ percentile is 78 percent, and the coefficient of variation (standard deviation divided by the mean) is extremely low at only 38 percent. The consumption of wheat is low in Hunan, with only $42 \mathrm{~g}$ of daily consumption per person on average, comprising just 8 percent of total caloric intake. By contrast, Gansu features almost the exact reverse pattern; wheat-based foods are the dominant staple, with $344 \mathrm{~g}$ of consumption per person per day, comprising 69 percent of total calories, whereas rice consumption is only $35 \mathrm{~g}$. And as in Hunan, the dominance of consumption of the staple is widespread; the $25^{\text {th }}$ percentile of the distribution of calorie share from wheat is 60 percent, the $75^{\text {th }}$ percentile is 80 percent, and the coefficient of variation is just 39 percent. Thus in both provinces, the relevant staple good is a dominant source of calories for most households. The total calorie share from all cereals or grains is 72 percent in Hunan and 77 percent in Gansu. The reliance on these basic foods for nutrition is underscored even more by the fact that in both provinces, on average 13 percent of calories come from edible oils (mostly vegetable oil), which is primarily used in cooking (and is generally not a substitute for other forms of consumption or nutrition). Thus, the consumption of all other foods combined on average contributes only 10 percent of calories in Gansu, and 15 percent in Hunan.

In both provinces, vegetables and fruit (predominantly cabbage in Hunan, and cabbage and potatoes in Gansu) are the second largest category of consumption based purely on quantity or bulk. Though overall, they contribute little to caloric intake (5 percent in Hunan and 7 percent in Gansu) due to the very low caloric value per gram of these foods. The remaining consumption of meat (primarily pork), pulses (primarily bean curd or tofu) and dairy (primarily milk) constitute about 10 percent of calories in Hunan and 4 percent in Gansu. In Hunan, the greatest share comes from meat, with 42 grams of consumption per person per day on average, comprising 7 percent of average caloric intake. By contrast, in Gansu meat consumption is significantly lower, averaging only 13 grams per person per day and contributing less than 1 percent of total caloric intake. Consumption of pulses is in fact greater than consumption of meat in Gansu. This is likely due to the lower levels of income in Gansu; pulses are often referred to as "poor man's meat" because they are a cheaper source of protein (again, when combined with other foods typically eaten as staples). Therefore, while the consumption patterns in Hunan 
match up well with the basic set up under which we predict Giffen behavior, in Gansu the patterns do not fit quite as well due to relatively low meat consumption.

\section{Estimation Strategy}

Given the random assignment of the price change and the panel nature of our survey, our basic strategy is to simply compare the household-level changes in dietary intake ${ }^{21}$ of the staple good for treatment and control groups. Since assignment to treatment and control groups was randomized within sample counties, we add county*time fixed effects, so that we are in effect comparing the changes for households with different subsidy levels within the same community. This strategy controls for any county-level factors that change over time, such as the prices of foods, labor market conditions or the value of government transfer programs.

We regress the percent change in intake of the staple good for household $i$ in period $t$ on the change in the subsidy (in percent). The percent change formulation normalizes for factors such as household size, composition, and activity level and allows us to interpret the coefficients as elasticities. For each household, we observe two changes: the change between periods 2 and 1 $(t=2)$, capturing the effect of imposing the subsidy, and the change between periods 3 and $2(t=$ 3), capturing the effect of removing the subsidy. Thus we estimate:

$$
\% \Delta \text { staple }_{i, t}=\alpha+\beta \% \Delta p_{i, t}+\sum \gamma \% \Delta Z_{i, t}+\sum \delta \text { County }^{*} \text { Time }_{i, t}+\Delta \varepsilon_{i, t}
$$

where $\% \Delta$ staple $_{i, t}$ is the percent change in household $i$ 's consumption of the staple good, $\% \Delta p_{i, t}$ is the percent change in the price of the staple due to the subsidy (negative for $t=2$ and positive for $t=3$ ), $\% \Delta Z$ is a vector of percent changes in other control variables including income (split into earned and unearned (government payments, pensions, remittances, rent and interest from assets) sources) and household size, and County*Time denotes a set of county*time dummy variables. We compute all changes as arc-percent-changes (i.e., $\left.100 *\left(x_{t}-x_{t-1}\right) /\left(\left(x_{t}+x_{t-1}\right) / 2\right)\right){ }^{22}$ The percent change in the subsidy is computed as 100 times the change in the subsidy divided by the average (net of subsidy) price of the staple good in the two corresponding rounds. The results

\footnotetext{
${ }^{21}$ While we also gathered data on food purchases and expenditures, actual daily intake is likely to be a better measure of consumption or demand. This is due to the fact that food is storable, purchases are lumpy or infrequent, and households' recall of what they ate the day before the survey is likely to be significantly more accurate than recall of purchases over the past month.

${ }^{22}$ We prefer the arc-percent-change specification over the simple percent change because the subsidies represent large changes and because the arc formulation has the desirable property of being symmetric over time. However, the results are largely unchanged if we use the simple percent change instead.
} 
are robust to a wide range of alternative specifications, some of which we discuss in section IV.B.

\section{Refining the Test for Giffen Behavior}

The discussion in section II highlighted a nuanced prediction of the standard consumer model in light of subsistence concerns. The poorest of the poor should have a negative price elasticity, the poor-but-not-too-poor may have a positive price elasticity, i.e., exhibit Giffen behavior, and the relatively wealthy should once again have a negative price elasticity. Although our primary concern in this paper is documenting the presence of Giffen behavior, we are also interested in testing this broader prediction of the theory.

Unfortunately, classifying households or individuals directly by consumption zone is not possible. Not only is there no consensus on what constitutes a subsistence level of calories, but any such threshold would certainly vary widely by age, sex, height, weight, body fat and muscle composition, level of physical activity, health status and a range of other factors. As a result, although we can compute caloric intake for each individual, identifying whether specific individuals are below, near or above their subsistence level of caloric requirements is not possible. For the same reason, it is not possible to define these regions based on income or expenditure; individuals with different characteristics will require different amounts of expenditures or income to achieve nutritional sufficiency. Any such cut-offs would be imperfect, including some people who, because of high weight or activity levels, are unable to achieve maintenance nutrition with the specified income, and excluding others who have lower than expected nutritional (and thus income) needs because of small stature or low activity levels.

The method of parsing the data we employ is based in the theory. Those who are so poor that they cannot achieve maintenance nutrition will consume a very high proportion of their food in the form of the staple good, regardless of size and activity level. Thus, splitting the data by the pre-intervention or initial share of caloric intake from consumption of the staple (Initial Staple Calorie Share, or ISCS) provides a more direct measure of whether a consumer or household is well-off enough that they could, potentially, exhibit Giffen behavior. This idea is illustrated in figure 2, which revisits the response to an increase in the staple price for households in the different consumption zones, as in figure 1. When the household or individual is so poor that they are at very low levels of caloric intake relative to subsistence need they will have a very 
high share of calories from the staple good; in this range, they respond to a staple price increase by decreasing consumption of that staple. As they become wealthier and move into the subsistence zone, the staple calorie share decreases, and in this range, they exhibit Giffen behavior. Finally, at even higher levels of wealth, they move into the normal consumption zone with downward sloping demand. Thus, in our test for Giffen behavior, we will want to segregate those households with the very highest levels of ISCS.

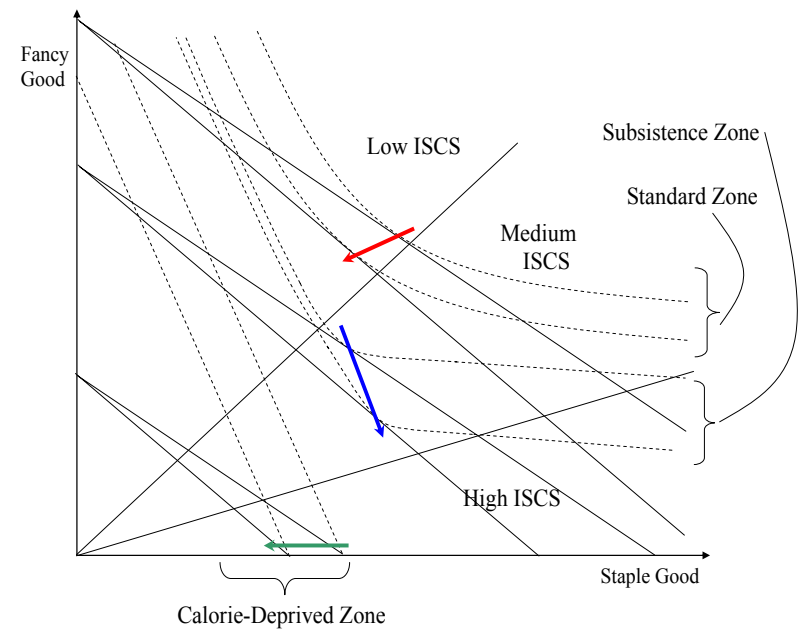

Figure 2. Consumption Path and the Staple Calorie Share

While just using ISCS does not overcome the problem of identifying the exact threshold cut-off for moving from the calorie-deprived to subsistence zones, the advantage of this measure is that it is more "need neutral," in that it normalizes for individual differences in caloric requirements. The measure also captures the simpler idea that if a household is so poor that it does not consume any of the fancy good, it cannot respond to a price increase by consuming less of it. While ISCS may not be a perfect indicator of whether a household is near the subsistence zone (because of unobserved taste variation, for example), we believe it to be superior to other available measures. $^{23}$

\footnotetext{
${ }^{23}$ The broad conclusions of our analysis hold if we instead use, say, staple budget shares to parse the data. However, we believe the ISCS is a more appropriate measure. First, expenditure data are notoriously noisy, especially due to large but infrequent purchases such as durable goods that can skew budget shares. By contrast, the diets of the households in our sample rarely contain more than 3 or 4 items and typically do not vary from day to day. Second, as shown, ISCS is not very need dependent, whereas budget share thresholds will vary considerably by household, due to differing housing, health care, education and nutritional needs. Further, while some expenditures such as entertainment are highly discretionary, others categories, such as housing, health care and utilities, are much less so. Thus, unlike the fairly precise ISCS cut-offs derived, clean cut-offs based on budget shares would be difficult to derive, since the amount of truly discretionary income is difficult to measure. These thresholds would therefore contain many classification errors. For example, households with schooling-aged children would appear "richer" by
} 
Exploratory calculations using a simplified version of a minimum-cost diet problem (see, for example, Dorfman, Samuelson and Solow 1958) for China suggest that the ISCS associated with a minimum-cost, nutritionally-sound diet (designed to ensure adequate consumption of calories and protein, and consisting of rice or wheat and bean curd) is much less variable than either required calories or required expenditure (details provided in the appendix). We compute the minimum cost diet for a range of weight/age/gender/activity level combinations, and find that the ISCS associated with the minimum-cost, nutritionally-sound diet only ranges between 0.79 and 0.86 in Hunan and 0.78 to 0.85 in Gansu. Consumers or households that are wealthy enough to be consuming a diet with a lower ISCS would seem to be those who could, in principle, exhibit Giffen behavior. In light of this, our baseline specification splits households based on whether their ISCS is less than 0.80 (this corresponds approximately to the $80^{\text {th }}$ percentile of the staple calorie share distribution). However, we also explore the robustness of the results to different thresholds.

While the theory suggests we should also exclude the wealthier households in the standard zone of consumption, unlike the threshold for segregating households that are too poor, it is unfortunately not possible to estimate the threshold for this region. Further, because our sample is drawn from the poorest households, there is no guarantee we even have any households in this zone. Therefore we begin by taking the conservative approach of only using the threshold excluding the poorest; if our theory is correct, if anything keeping the lower tail of the staple calorie share distribution will make it less likely we find Giffen behavior, since we are potentially including households with downward sloping demand among our potential Giffen consumers (we explore this possibility in section IV.C).

\section{RESULTS}

\section{A. Hunan}

The estimation results for equation (1) for Hunan are presented in table 4. For all regressions, we present standard errors clustered at the household level. Starting with the full sample of households and excluding all other controls, in column 1, a 1 percent increase in the price of rice causes a 0.22 percent increase in rice consumption (i.e., consumption declines when

the budget share measure because of expenditures on school fees; however, these expenditures are not really discretionary, and in fact make the household less "wealthy" than an identical household not facing these fees. 
the subsidy is added, and increases when it is removed). ${ }^{24}$ While the estimate of the elasticity is positive, the coefficient is not statistically significant at conventional levels (the p-value is 0.14 ). Column 2 adds changes in income (earned and unearned) and household composition. Controlling for these other variables will help absorb any residual variation, and isolate the "pure" price effect of the intervention, as opposed to any behavioral effects the intervention may have on household size or either source of income (though in regressions for both provinces and for all population subgroups, the effect of the subsidy on these other variables is small and not statistically significant, suggesting the treatment had no such behavioral effects). Adding these other control variables changes the results only very slightly, increasing the coefficient and improving precision. While this coefficient is only statistically significant at the 10 percent level, it provides our first suggestive evidence of Giffen behavior in Hunan. And as would be expected for households exhibiting Giffen behavior, the income effect is negative for unearned income, confirming that rice is an inferior good. The point estimate of the elasticity of unearned income is small, though there is likely to be significant measurement error in this variable, biasing the coefficient towards zero. ${ }^{25}$

However, as we have emphasized, Giffen behavior is only likely to be exhibited by a specific subset of the poor. Therefore, in columns 3 through 6 we refine the test by parsing the data according to the theory, separating households by whether their pre-intervention staple calorie share suggests they are likely to be too poor to purchase something other than rice. For the group consuming at least some substantial share $(20 \%)$ of calories from sources other than rice (column 3), i.e., the poor-but-not-too-poor, we find very strong evidence of Giffen behavior. A one percent price increase causes a 0.45 percent increase in consumption, and the effect is statistically significant at the 1 percent level (and little changed by adding in the other control variables). Thus, as theorized by Marshall and others, when faced with an increase in the price of the staple good, these households do, indeed, "consume more, and not less, of it (Marshall, 1895)."

\footnotetext{
${ }^{24}$ Although our intervention caused a price decrease between rounds 1 and 2 and a corresponding increase between rounds 2 and 3, for ease of exposition and interpretation we will typically refer to the effects of a price increase, the more traditional and intuitive way of describing Giffen behavior.

${ }^{25}$ The coefficient on earned income is positive (though also small); however, since greater caloric intake may improve productivity and earnings (Thomas and Strauss, 1997), especially among those with very low nutritional status, this coefficient may be biased due to endogeneity. Unfortunately, we lack convincing instruments for changes in earned income. Dropping this variable does not change the results.
} 
By contrast, but again consistent with the theory, the group consuming more than 80 percent of their total calories from rice (i.e., those still largely unable to consume meat), respond in the opposite direction (columns 5 and 6), with a large decline in rice consumption. Since these households consume essentially only rice, they have no choice but to respond to an increase in the price of rice by reducing demand. Thus, beyond finding evidence of Giffen behavior, the results also provide initial support for the subsistence model underlying such behavior. We find Giffen behavior where the theory predicts it, and downward sloping demand elsewhere. We explore the subsistence model further in section IV.C below.

\section{B. Robustness}

The finding of Giffen behavior is robust to a wide range of alternate specifications, shown in table 5. Since including the change in household size or either source of income rarely makes more than a marginal difference on our estimates of the price elasticity, for conciseness of presentation we show only the result with these additional control variables included. Columns 1 to 3 present results from a log-log specification, regressing the change in the log of household rice consumption on the change in the log of the net-of-subsidy price of rice and changes in the logs of the other control variables. The results again reveal Giffen behavior for households consuming less than 80 percent of their calories from rice, and downward sloping demand for those above this threshold. The point estimates of the elasticities are much greater here than for the arc percent changes in table 4 . However, this difference is largely attributable to the greater weight given to very low values with a log specification; for example, if we trim just the lowest 1 percent of rice consumers in Hunan, the price elasticity coefficients are almost identical to those in table $4(0.229(0.183), 0.461(0.218)$ and $-0.558(0.250)$ for the full sample and the less than and greater than 80 percent staple calorie share groups, respectively). Returning to our main specification for the independent variables (equation 1) but using the level change in rice consumption per capita (rather than total household consumption) ${ }^{26}$ as the dependent variable (columns $4-6$ ) or the percent change in consumption using individual-level data (adults only; columns 7 -9) again reveals Giffen behavior for the group with less than 80 percent calorie share (though the results for those with greater than 80 percent, while negative, are no longer statistically significant).

\footnotetext{
${ }^{26}$ Using the percent change in consumption per capita yields nearly identical results to those in table 4.
} 
To explore the robustness of the conclusions to an alternative way of classifying households into consumption zones, columns 10 - 13 return to equation (1) but split households by pre-intervention expenditure per capita. ${ }^{27}$ As described earlier, due to variations in individual and household characteristics, we believe expenditure to be an inferior method of classifying consumers into different consumption zones. Nevertheless, doing so provides a useful robustness check. Lacking in this case a threshold based on a cost minimization problem, we simply stratify households based on whether they are above or below the $15^{\text {th }}$ or $25^{\text {th }}$ percentile of the expenditure distribution. We again see evidence of Giffen behavior among the poor-but-not-toopoor. Those above the bottom quartile (column 10) respond to a one percent increase in the price of rice by increasing rice consumption by 0.29 percent, though the effect is statistically significant at only the 10 percent level. And unlike the case of stratifying by staple calorie share, the poor group in this case does not decrease consumption in response to a price increase; this is likely due to the relative imprecision of relying on the expenditure-based threshold. Using the $15^{\text {th }}$ percentile cut-off, we see strong evidence of Giffen behavior for the poor-but-not-too-poor, and now the coefficient for the poorest is negative, though it is not statistically significant.

As a final robustness check, since the 80 percent threshold for the rice calorie share was a rough approximation based on a minimum-cost diet calculation, table 6 shows the original regressions using alternative thresholds. As the threshold varies from 70 to 90 percent, the point estimate of the elasticity for those below the threshold varies only from 0.27 to 0.47 , with statistically significant coefficients in all cases. Therefore, the results point convincingly and robustly to the conclusion of Giffen behavior in Hunan. Additionally, as might be expected from the subsistence model, the coefficients broadly increase as the staple calorie share threshold declines from 0.90 to 0.75 , as we are in effect excluding more and more of the least well-off, i.e., those most likely to respond to a price increase by decreasing consumption. The coefficients for each corresponding group above the threshold staple calorie share are negative for all thresholds up to 0.70 ; however, due in part to the smaller sample sizes in some of the cases, the effects are only statistically significant at the 10 percent level or better for the 75,80 and 85 percent thresholds. The increase in the coefficients as the threshold moves from 0.85 to 0.70 is consistent

\footnotetext{
${ }^{27}$ Ideally, we would use the data from each particular round to assess living standards rather than using only the preintervention data, since Giffen behavior depends on a consumer's budget at the time they make their decisions. However, expenditure in the round with the subsidy is obviously endogenous with respect to the subsidy; income would encounter enodgeneity as well (the increased consumption afforded by the subsidy might affect earnings).
} 
with increasingly including some of the least poor of the poor who are in the subsistence rather than the calorie-deprived zone, for whom the response to a price increase is positive.

Thus, overall, across a range of specifications, alternative thresholds and ways of classifying households into consumption zones, the results point to robust evidence of Giffen behavior with respect to rice in Hunan. ${ }^{28}$

\section{Exploring the Subsistence Model and Refining the Giffen Zone}

Beyond providing evidence of Giffen behavior, our study aims to document more broadly the behavior of extremely poor households in order to highlight some key insights relevant for academics and policymakers. We have already seen that consumers with very high staple calorie shares (i.e., the poorest-of-the-poor) do not exhibit Giffen behavior. In addition, the model also predicts that once consumers are wealthy enough to pass beyond the subsistence zone into the standard consumption zone, staple demand should once again slope downward; in effect, we predict an inverted-U shape, with downward sloping demand (negative coefficients) for low and high values of staple calorie share, and Giffen behavior (positive coefficients) for intermediate values. $^{29}$ As stated, unlike the 80 percent calorie share, it is not possible to define a threshold beyond which households are likely to be in the standard or normal consumption zone, nor are we even certain our sample of the urban poor contains any such households. We therefore take a simple, flexible approach using a series of locally weighted regressions. At each staple calorie share point from 0.30 to 0.95 (there are few observations below 0.30 or above 0.95 ), we estimate equation (1) using a window of staple calorie shares of 0.10 on either side of that point; within that window we estimate a weighted regression, where observations closest to the central point receive the most weight (we use a biweight kernel, though the results are robust to alternatives). Figure 3 plots the resulting coefficients on the arc percent price change variable (i.e., the price elasticity) at each initial staple calorie share point for Hunan, along with the associated 95 percent confidence interval. The basic inverted-U shape in staple calorie share is clear. The elasticity is negative for the lowest and highest staple calorie shares, and positive in between.

\footnotetext{
${ }^{28}$ Two additional refinements are worth reporting. First, if we include an interaction between the subsidy and round variables, in all cases we cannot reject the hypothesis that the effects are equal for adding vs. removing the subsidy. Second, we find Giffen behavior separately for male and female headed households, though the threshold at which the effects are statistically significant is lower for male headed households.

${ }^{29}$ Though, if we do not have enough households wealthy enough to fall into the normal consumption zone, we expect that the coefficients should at least decline as staple calorie share declines.
} 
The Giffen range, where the point estimate of the elasticity is positive, reaches from 0.53 to 0.84 (which includes nearly two-thirds of the Hunan sample) though it is only statistically significant from 0.63 to 0.75 . The peak of the curve reaches an elasticity of 0.85 , at a staple calorie share of 0.70 . And the threshold at which the elasticity turns negative is 0.80 , which matches surprisingly well our simple minimum cost diet calculation. In general, the precision of these estimates is lower than those observed in tables 4 to 6 , since here we are restricting each regression to a band of \pm .10 around a particular point, which reduces the sample size.

Not only does this figure support the theory in that Giffen behavior is most likely to be found among a range of households that are poor, but not too poor or too rich, it also guides us to a particular range when theory cannot provide a specific set of thresholds, as with the threshold between the subsistence and normal consumption zones. In particular, this curve suggests we restrict the range in which we test for Giffen behavior not just to those with a staple calorie share less than 0.80 , but also to those with at least, say, 0.60 . In column 7 of table 4 , doing so increases the point estimate of the elasticity dramatically, from 0.47 to 0.64 , as we are in effect removing the wealthiest households. ${ }^{30}$ And even with the smaller sample, the effect is statistically significant at the one percent level, again strongly supporting the conclusion of Giffen behavior in Hunan.
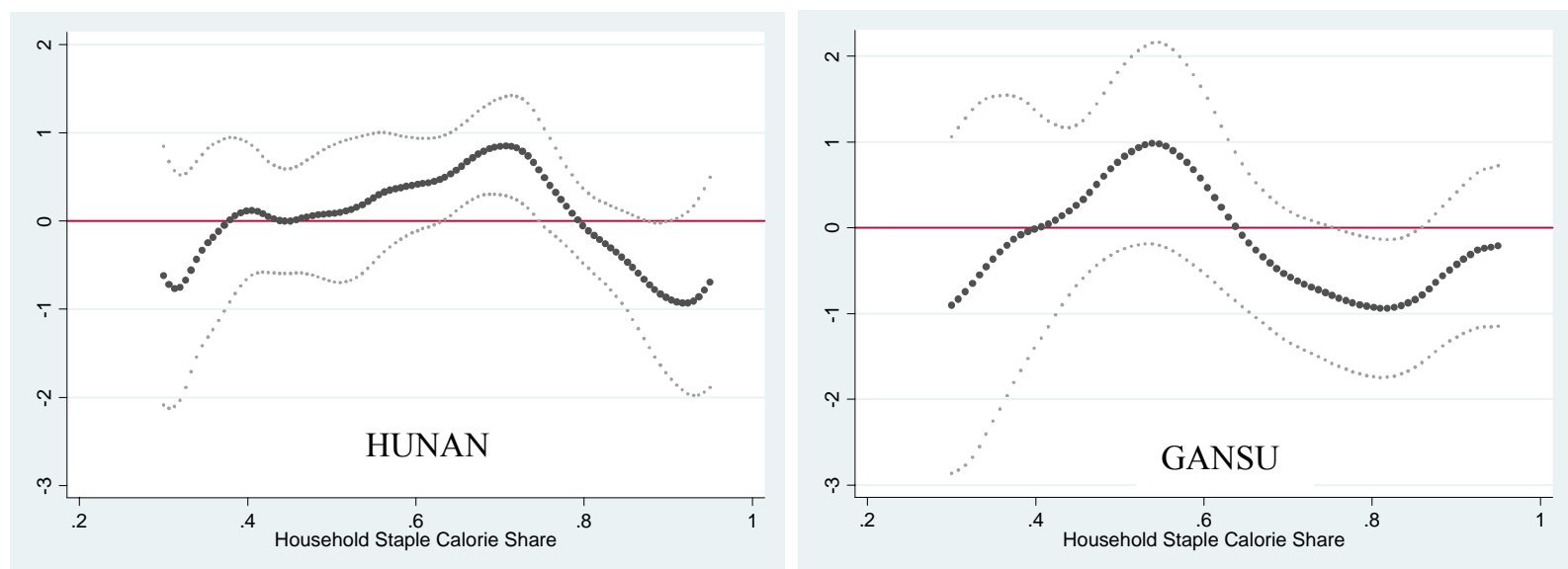

Figure 3. Coefficient Plots

A second prediction of the subsistence model we can explore is that in response to an increase in the price of the staple good, consumers facing a subsistence constraint will not only

\footnotetext{
${ }^{30}$ This coefficient differs slightly than the peak coefficient in the figure since the latter arises from a weighted regression, with more weight assigned to the points closer to the peak of the curve.
} 
consume more of the basic good, but will also consume less of the fancy good, which we identified here as meat. Column 8 of table 4 shows regressions like (1) above, but using the arc percent change in meat consumption as the dependent variable (we focus on the sample of households with less than 80 percent rice calorie share, though the results are robust to other thresholds). We find that the point estimate of the elasticity of meat consumption with respect to the price of rice is negative as predicted, though it is not statistically significant. However, one limitation of this analysis is that in Hunan, only about 45 percent of households reported meat consumption. ${ }^{31}$ Therefore, in column 9 we focus on households that consume at least $50 \mathrm{~g}$ of meat per person in round 1 , which is still a very modest amount. ${ }^{32}$ Here, the results are more evident; a one percent increase in the price of rice leads to a large (1.13 percent), statistically significant decrease in meat consumption, as predicted by the model.

Thus, again, while our primary goal was to document the existence of Giffen behavior, these two results (the inverted- $U$ shape of the response of rice consumption to a change in price and the decline in meat consumption in response to a change in the price of rice) support the subsistence model of consumption with a staple good and a taste-preferred but more expensive source of calories (such as meat) outlined above.

\section{Gansu}

As shown in table 3, wheat-based foods (primarily buns, the simple bread mo, and noodles), are the staple good in Gansu. However, not all wheat-based foods are made at home from flour; most notably, noodles are often either consumed at restaurants or road-side food stalls, or purchased from shops as a prepared or packaged food. Since the subsidy we provided applied only to the purchase of wheat flour, for our analysis we use only the consumption of wheat foods typically produced at home from flour. ${ }^{33}$ And, as suggested by the calculations in the appendix, because there is some consumption of these other forms of wheat, our threshold

\footnotetext{
${ }^{31}$ Though we condition on the staple calorie share in our regressions, the residual is not simply calories from meat.

${ }^{32}$ While it may seem natural to have run all the specifications above stratifying based on meat consumption rather than staple calorie share, the latter is more general and does not rely on our ability to specifically identify meat as the (only) fancy good.

${ }^{33}$ Over 90 percent of the consumption of wheat-based foods in Gansu was reported as "wheat flour," with most of the remainder reported as noodles. However, we cannot rule out that some noodles were made at home from flour but recorded as noodles, or that some consumers mistakenly reported purchased bread as wheat flour.
} 
staple calorie share for Giffen behavior based on wheat flour alone is closer to $0.70 .^{34}$ Table 7 presents the main results. In contrast to the case of Hunan, the coefficient is negative for the full sample in column 1. Even with the refined test, focusing on those below the staple calorie share threshold of 70 percent, while the coefficient is positive, it is extremely small and not statistically significantly different from zero. In addition, there is no evidence that wheat is even an inferior good in these cases.

Looking across alternative thresholds in columns 4 through 10, we do find that the coefficients increase and ultimately turn positive as the staple calorie share decreases toward 60 percent, consistent with excluding more and more households that are likely to be below the subsistence consumption zone; however, the coefficient then abruptly declines when the share is lowered to 55 percent, and in none of the cases are the coefficients statistically significant.

As the model suggested and the analysis of Hunan revealed, focusing only on those below a certain staple calorie share threshold risks including those who may be too wealthy to be Giffen consumers. While in Hunan we were able to detect Giffen behavior even under the more conservative approach (i.e., without appropriately parsing the data), it may be that we are simply unable to in Gansu. Returning to figure 3, as in Hunan the coefficients from the weighted regressions for Gansu reveal an inverted-U response of wheat consumption to an own-price change over the range of initial staple calorie share, though no coefficient is statistically significantly different from zero at the five percent level over this interval. The range of positive point estimates is both lower and narrower than in Hunan, ranging only from approximately 0.40 to 0.60 ; correspondingly, column 11 of table 7 shows that if we examine households in this range, there is evidence of Giffen behavior, with a large elasticity (1.07), statistically significant at the 10 percent level. While we are of course concerned about the inherent biases in searching over many intervals for a result, both the theory outlined above and the pattern observed in figure 3 point to the need to examine only those who are poor, while excluding those who are too poor and not poor enough, in testing for Giffen behavior. If not as compelling as the evidence in Hunan, the results are at least strongly suggestive of Giffen behavior in Gansu.

Without discounting this last result, we turn now to consider possible explanations for why the evidence of Giffen behavior in Gansu is less immediately evident and precisely

\footnotetext{
${ }^{34}$ Alternatively, we could use a staple calorie share of 0.80 based on consumption of all wheat foods, rather than just those produced at home from flour.
} 
estimated than in Hunan. The earlier discussion suggested that Giffen behavior is most likely to be found among consumers whose diet consists primarily of a single staple good, with relatively few substitutes, and a fancy good, which is taste-preferred but a more expensive source of nutrition. We consider two potential failures of these conditions in Gansu. First, in our sample there is very little consumption of the fancy good, meat. ${ }^{35}$ As shown in table 3 , households in Gansu receive on average only 1 percent of their calories from meat, which is even less than the 7 percent observed in Hunan; further, only one-quarter of households reported any meat consumption in our first period consumption diary. The bulk of non-staple calories come largely from vegetables (especially potatoes, which themselves may potentially be a staple food) and oil, neither of which are likely to be considered a fancy good. With little consumption of the fancy good it is perhaps not surprising that most households do not behave like Giffen consumers in Gansu. There is simply no way for them to finance additional purchases of rice by reducing meat, since they are consuming almost no meat to begin with. ${ }^{36}$ This also suggests that the best place to find Giffen behavior is among those consuming a nontrivial amount of meat. Therefore, in column 1 of table 8 , we consider only households that consume at least 50 grams of meat per person in the initial period. Though the sample shrinks considerably because meat consumption is so uncommon, we do find evidence of Giffen behavior among this group, with a 1 percent increase in the price of wheat causing a 1.3 percent increase in wheat consumption.

Gansu also departs from the ideal conditions for Giffen behavior in that wheat as a staple is consumed in a number of other forms that may act as substitutes for each other, many of which are not made directly by consumers at home from wheat flour. Unfortunately, our experimental design failed to account for this additional complexity. ${ }^{37}$ In Hunan, the staple good, rice, is consumed typically only in its basic form. By contrast, in Gansu wheat is consumed as mo and buns made at home, plus noodles, and other wheat-based, prepared foods like bread, biscuits or

\footnotetext{
${ }^{35}$ This result was unanticipated, since the northern provinces in our original paper (Jensen and Miller 2002), and our field test of the survey for the current study, revealed considerably more meat consumption in Gansu.

${ }^{36}$ While there is some consumption of pulses and, to a lesser extent, dairy, these goods are also unlikely to be regarded as fancy goods in the way that meat is, since most households turn to these goods only when they cannot afford meat. Further, there is no way to cut back consumption of these foods while maintaining protein intake; with meat, households can reduce consumption but switch to pulses as a less expensive source of protein.

${ }^{37}$ Though in selecting sample sites, the authors personally only visited two of the counties in Gansu (Anding and Yuzhong); these counties, both with significant Muslim populations who traditionally consume primarily the home made bread $m o$, fit the pattern better, with $88 \%$ of all wheat consumption coming from flour, compared to $74 \%$ in the other three counties. If we limit our analysis to just these two counties, we find a positive coefficient for all staple calorie share thresholds, though due to the smaller samples, the coefficients are not statistically significant.
} 
deep-fried dough purchased from shops or food stalls. While table 3 showed that average pretreatment wheat consumption per capita in Gansu was 344g, typically about 34 grams, or 10 percent, of that wheat is from items other than $m o$ or buns. If a household consumes their staple food in many forms and the price of one increases, they may not need to engage in Giffen behavior because they can reduce consumption of that one and increase consumption of the other, substitutable forms of the staple that did not experience the price increase. While this is unlikely to happen often in reality because the price of all the forms of the staple will be linked to the price of the raw ingredient (here, wheat), the unique structure of our subsidy did just that, subsidizing only the form of the staple prepared at home, and not the close substitutes purchased in stores. This may both explain why we do not find widespread evidence of Giffen behavior in Gansu, and also suggests we might find such behavior if we focus on those households where consumption of these other forms of wheat is small or zero in the initial period. ${ }^{38}$ Column 2 of table 8 provides some suggestive evidence of this possibility, focusing on the condition that the household consumes less than 50g of these alternative forms of wheat. Among this group there is again statistically significant evidence of Giffen behavior, with a very large elasticity.

Overall then, while the results for Gansu do not yield as evident, robust evidence of Giffen behavior as was found for Hunan, we believe this is most likely due to our failure to recognize ex ante that for the majority of households in our sample, diets do not conform to two of the basic conditions under which we predict Giffen behavior (consumption of a fancy good, and a staple good for which there are no close substitutes). When we restrict our sample to take these factors into consideration, we do find evidence of Giffen behavior, though the samples are smaller, precisely because most households do not conform to the conditions in Gansu. It is possible that if we sampled a slightly wealthier group of households that consume more of the fancy good, and perhaps altered our experimental design (e.g., to subsidize all wheat foods, not just wheat flour), we might find stronger evidence of Giffen behavior.

\section{E. Addressing Potential Alternative Explanations for the Results}

The analysis so far provides robust evidence that price subsidies for rice caused decreases in rice consumption in Hunan, with somewhat weaker evidence for wheat in Gansu. However, there are two alternative explanations for these results beyond Giffen behavior that need to be

\footnotetext{
${ }^{38}$ Some of this variation is geographic or based on religion, as noted above.
} 
explored. First, there is the possibility that households viewed the vouchers as a signal about the value of the staple good. For example, consumers might interpret a subsidy as an attempt to encourage people to eat more of the good, perhaps because of its health benefits. Alternatively, there may be a behavioral effect whereby the vouchers enhance the salience of the staple good, or where households feel that they should eat more of it in order to take advantage of the subsidy before it runs out. However, in these cases we would expect the vouchers to increase consumption, the opposite of what is observed as Giffen behavior. Alternatively, and perhaps less likely, households may view the vouchers as providing adverse information about the staple good; for example, they may view the attempt to sell more rice as an indication that there is something wrong with the current stock, in which case they might want to consume less of it (though consumers were told the subsidies were being provided by outside researchers rather than merchants, farmers or the government). But since the effects varied by the staple calorie share, to explain our results it would have to be that the vouchers had a salience or signal effect only for some subset of households based on their calorie share (or there was a signal to all households, but only some were in a situation that allowed or required them to respond to it), which seems less likely. ${ }^{39}$

A second concern is the possibility that households cheated, ${ }^{40}$ for example by swapping vouchers for cash instead of using them for purchases of the staple good, ${ }^{41}$ or reselling rice or wheat purchased with the vouchers at a higher price. In the extreme case where all vouchers are sold for their full face-value, the voucher program would have been a pure wealth shock, and consumption of an inferior good like rice or wheat would be expected to decline even though the

\footnotetext{
${ }^{39}$ If the consumption of the treatment groups responded both to having received any subsidy at all (i.e., the signal or salience effect) and to size of the subsidy received, we could eliminate the former and identify the elasticity off of the size of the subsidy alone by running regressions excluding the control group. Doing so yields similar results, including continued evidence of Giffen behavior. For example, for Hunan, the price elasticity for the full sample is $0.33(0.22)$; for ISCS less than 0.80 it is $0.61(0.25)$ and for ISCS greater than 0.80 it is $-0.75(0.44)$. Similar results hold for Gansu, though as above, the estimates are less precise and in some cases we cannot reject zero even though the point estimates have the correct sign. These results indicate that the Giffen effect is not driven by some common signaling or salience effect among the treatment groups. However, it is of course possible that larger subsidies create stronger signaling effects, so these results do not imply there were no such effects at all.

${ }^{40}$ Cheating where shopkeepers do not provide the full subsidy to consumers (for example, those with poor math skills) effectively lowers the value of the subsidy, so the Giffen behavior we find would likely have been even stronger had such cheating not occurred.

${ }^{41}$ Most shopkeepers sold only grain, so most households could not have exchanged the vouchers for other foods.
} 
effective price of these staples had not changed. In less extreme cases, selling only some of the vouchers at less than face-value would have exaggerated the wealth effect of the subsidy. ${ }^{42}$

Preventing cashing out of the vouchers was one of our primary concerns in designing the intervention. However, in doing so we also wanted to ensure that the process of redeeming the vouchers would be as much like an ordinary market transaction as possible, and to keep the administrative burden of the intervention manageable. In addition, while we wanted to prevent cashing out of vouchers, we also wanted to allow for the fact that a natural reaction to receiving access to discounted rice or wheat would be for households to build up their stores of these goods, which ostensibly might look very similar to cashing out (i.e., the number of vouchers redeemed is far in excess of the amount of rice or wheat people report consuming).

With these concerns in mind, a number of safeguards were built into the experimental design. As mentioned earlier, the consent scripts given to the households in the treatment groups stated that they were explicitly prohibited from selling the vouchers or the rice or wheat bought with the vouchers. Households were also told that there would be periodic monitoring of their compliance, and that any households found to be violating this condition would be dismissed from the program. Our native Chinese implementation team, which is very familiar with the population from which our survey households were drawn, felt that in light of such a rule the intervention households would be very unlikely to cash out the vouchers (although they would be likely to spend vouchers to build up their stores).

One fifth of the total vouchers were distributed to households each month, although all vouchers remained valid until the end of the intervention. Because of this, households engaging in early cashing out would be limited in their ability to do so (since they only had a small part of the vouchers in hand) and would face losing the value of all future vouchers if they were caught. For our purposes, the crucial question is whether there was cashing out before the second round of the survey, since this is the only round for which the subsidy was in effect; cashing out of vouchers after the second survey would not significantly affect our results, since the third round of the survey was not administered until two months after the intervention's end, by which time the households would have presumably exhausted much of the benefit of the subsidy (either in

\footnotetext{
${ }^{42}$ If households bought rice at subsidized prices on behalf of (or as a gift to) their friends or relatives but do not make a profit from doing so, this does not affect the households' wealth and thus does not bias our experiment. We of course cannot rule out that treatment households shared some of their rice with others. However this "leakage" would tend to diminish the likelihood of finding Giffen behavior, since the effective value of the subsidy is reduced.
} 
the form of legitimately stored rice or wheat, or in income from cashing out vouchers). At the time of the second-round survey, a significant amount of the benefit of the program still lay in the future, which would therefore have reduced households' incentives to engage in cashing out.

In addition, since households consume so much of the staple, it is unclear they would gain much by trading the vouchers for cash, since they would be unlikely to receive the full cash value of the vouchers, and much of the cash received would eventually be used to purchase more of the staple (for which they would now have to pay a higher price, having sold away their vouchers). Faced with the sanctioned opportunity to purchase the staple at the subsidized prices and store it, or the prohibited opportunity to cash out the vouchers, it seems that for many households the risks associated with the latter would outweigh the potential gains. ${ }^{43}$

The participating shopkeepers were also given incentives to prevent cashing out. While they were compensated for the cost of the vouchers, they were also given a lump sum payment at the end of the intervention, and told that they would only be paid if they were found to have complied with the guidelines for the intervention, which included preventing resale and/or cashing out of vouchers. In order to ensure that only intervention households were allowed to redeem vouchers, redeemers were required to sign the vouchers (which were printed in Beijing in multi-color ink and bore a special stamp, making them difficult to counterfeit in the survey regions) at the time of redemption. These signatures were later audited by our managers to check for authenticity of the vouchers and legitimacy of the household signatures before making reimbursement payments to the shopkeepers. ${ }^{44}$

The payments were made to shopkeepers in two stages. The first payment was made soon after the second round of the survey (around 3.75 months into the intervention). The second payment, which included both reimbursement for the vouchers used after the second round of the survey and a bonus for compliance, was made after the intervention ended. Thus, over the time period up to and including the second round of the survey, the shopkeepers, knowing that they would lose their final bonus if they were found to have cheated, had a strong incentive to prevent cashing out at the time of the second round of the survey. Indeed, if they could be persuaded to

\footnotetext{
${ }^{43}$ Recall that storage itself is not a particular concern for our experiment, since we use intake data rather than purchase data as our measure of demand. There may be concerns about a behavioral effect whereby having more of the staple on hand encourages you to eat more, such as due to a lack of self-control; however, if this were happening we would expect consumption to increase in response to the subsidy, not decrease.

${ }^{44}$ Our Chinese management team was the residual claimant on the value of unredeemed vouchers, and so they, themselves, had a strong incentive to enforce the rules of the intervention and prevent cashing out.
} 
participate in such a venture, they would likely only do so if they gained a significant portion of the proceeds, which means that, to the extent that households were able to cash out vouchers, their gains would be reduced, further reducing their incentive to do so.

The safeguards discussed above were accompanied by monitoring and auditing to check for compliance. These audits did not discover any such cheating, and our survey personnel, who visited the households, did not discover evidence of cashing out. Finally, comparing voucher redemptions relative to estimated consumption and storage suggests that to the extent it occurred at all, cashing out could not have been significant or widespread (details provided in the appendix).

\section{F. Policy Implications}

A broader contribution of the theoretical discussion and results presented is highlighting the significant heterogeneity in consumption behavior among the poor, as summarized in table 9. While those in the subsistence zone respond to an increase in the price of a staple good by eating more of it, those above and below respond by eating less. These differing consumption responses are driven largely by differences in the wealth elasticity of demand for the staple. For those in the calorie-deprived zone, the wealth elasticity is positive, i.e., the staple is a normal good. For those in the subsistence zone, the staple good is inferior (indeed, it must be strongly inferior if demand is Giffen over this range). Finally, as the consumer moves into the standard zone, the staple once again becomes normal (though for sufficiently wealthy consumers, the elasticity is likely to be small).

\begin{tabular}{lccc}
\hline \hline & \multicolumn{2}{c}{ STAPLE DEMAND } & CALORIES \\
Zone & Price Elasticity & Wealth Elasticity & (Staple) Price Elasticity \\
\hline Calorie-Deprived & $(-)$ & $(+)$ & $(-)$ \\
Subsistence & $(+)$ & $(-)$ & Ambiguous \\
Standard & $(-)$ & $(+$, Small $)$ & $(+$, Small) \\
\hline
\end{tabular}

Table 9. Elasticities by Consumption Zone

The underlying heterogeneity in the response of staple demand to price changes will translate into differential nutrition responses to those changes. For those in the calorie-deprived zone, since a decline in the price of the staple good increases consumption of the staple, calories 
will increase. For those in the standard zone, the effect on calories is again likely to be positive, but quite small. For those in the subsistence zone, however, the direction of this effect is theoretically ambiguous. Consumers in the subsistence zone behave as if they are maximizing the non-nutritive aspects of food subject to the constraint that their calorie consumption stay above subsistence (this point is further elaborated upon in the appendix). A staple price decrease allows them to achieve subsistence with more discretionary wealth left over, and this "savings" will be used primarily to increase the non-nutritive aspects of the diet, rather than calories. The result is that the price decline may have relatively little effect on nutrition. In fact, it is possible that as the consumer starts to focus less on basic nutrition and more on taste or enjoyment, nutrition will even fall as the consumer starts to eat more "luxury" foods such as meat, sugars or restaurant meals. Such a case is illustrated in figure 4, which isolates the subsistence zone from figures 1 and 2. Demand at the initial prices for the basic and fancy good is at point A. When the price of the basic good decreases, demand shifts to point B. Notice that since B is on an isocalorie line to the left of $\mathrm{A}$, the consumer gets fewer calories after the staple price decreases.

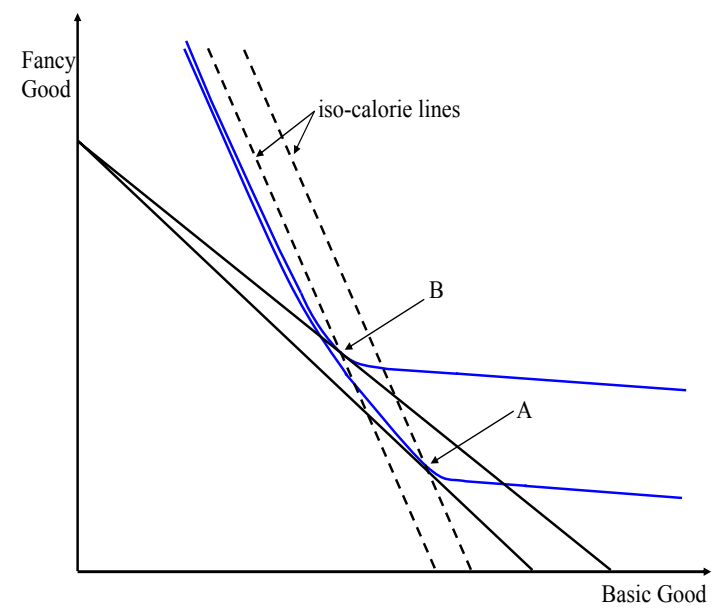

Figure 4. A Price Subsidy that Decreases Calories

These nutrition predictions can be considered in light of the large literature concerned with the response of calories to changes in wealth (see Strauss and Thomas 1995 and Deaton 1997 for reviews). These studies are motivated by the important question of whether (or by how much) nutrition will improve with economic growth, given the types of substitutions across foods highlighted above. The present discussion is related to this literature in that the core of our argument is that when households consume a great deal of the staple good and are extremely 
poor, changes in the staple price in effect create substantial real wealth effects. Thus, despite the fact that our analysis focused on price changes, similar concerns about the calorie response arise. However, our analysis yields two predictions that have not arisen in this previous literature, namely a heterogeneous calorie response by wealth (i.e., across the three zones), and in particular a possible decline in caloric intake over some wealth range.

We can directly examine the effect of our staple price subsidy on nutrition by merging the food intake data with the nutritional information from the Food Composition Tables to compute caloric intake for individuals and households in our survey. In figure 5, we present the coefficient plots (i.e., the price elasticities of calories) from smoothed regressions like those in section IV.C, where the dependent variable is now the percent change in household caloric intake. For both Hunan and Gansu, the inverted U-shaped heterogeneous response across those in the calorie-deprived, subsistence, and standard zones persists when looking at nutrition. Both the poorest of the poor and those above the subsistence zone (who are still quite poor) react to an increase in the price of rice by decreasing caloric intake. However, those in the subsistence zone actually increase their total calories. In other words, as the theory suggested was possible, the price subsidy caused a decline in caloric intake among this group (though the effect is not statistically significant over any range for Gansu).
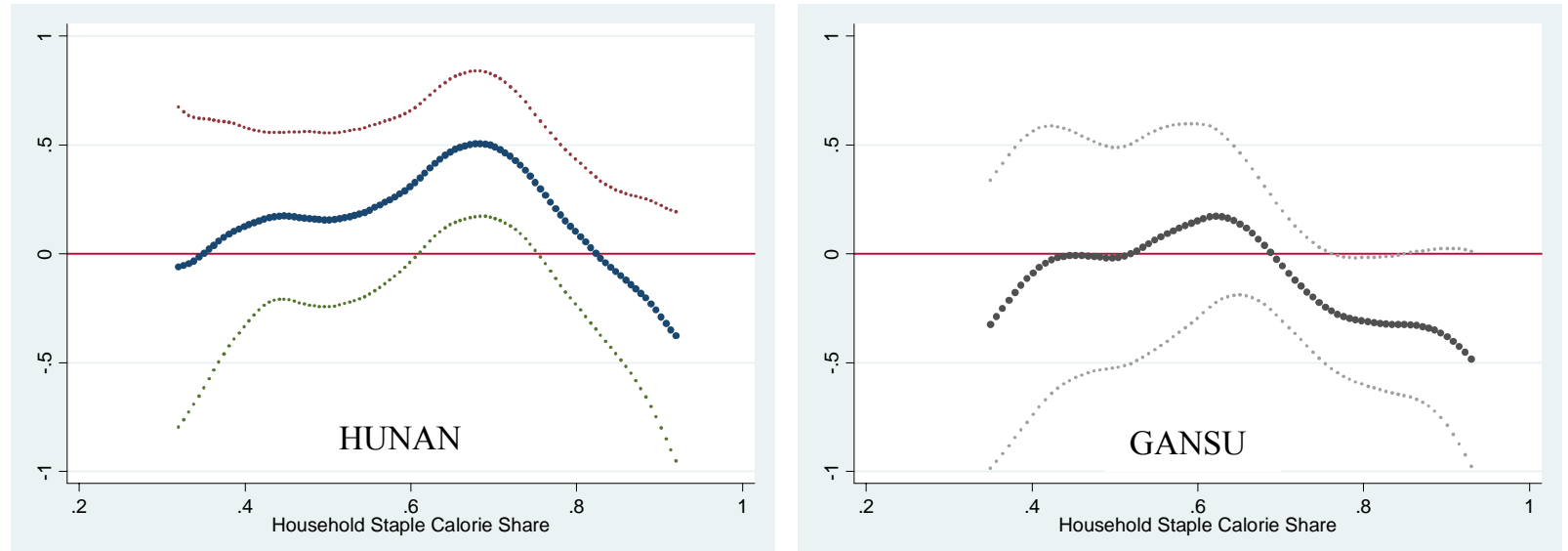

Figure 5. Coefficient Plots: Caloric Intake

These results have obvious and important policy implications. For example, a price subsidy or price controls for a staple good designed to improve nutrition will have the desired effect for the poorest-of-the-poor and the least-poor-of-the-poor; though even in these cases, the 
elasticities presented in figure 5 are quite small, suggesting only limited calorie improvements. ${ }^{45}$ However, a subsidy will cause a decline in caloric intake for the subsistence-zone consumers; this is particularly important given that nearly two-thirds of our sample of households officially classified as urban poor fall in this zone. While the subsidy would still have a positive utility effect for these households, to the extent that the aim of the policy is to improve nutrition, it may have exactly the opposite effect than was intended. Further, some of those utility gains may come through increased consumption of alcohol, tobacco or other goods that such policies, even if they do not actively discourage, usually are not intended to encourage.

It is also important to note that the difficulties facing subsidies or price controls would apply to almost any other program whose goal is to improve nutrition. In particular, any program that results in an increase in real wealth, whether through cash transfers, employment schemes, in-kind transfers or food stamps, will generate similar effects; households in the subsistence zone will decrease caloric intake.

The results are also important in light of the policy implications of the earlier studies of the income elasticity of demand for calories. Those policy makers who wish to increase nutrition but believe the income elasticity is small might be inclined to suggest, as alternatives to cash transfers, subsidies or price controls that directly encourage increased consumption of nutritious foods. Similar policy prescriptions may arise if there is a concern, often stated, that simply giving cash is not desirable because households may spend it on other luxuries (food or non-food). Our results indicate that even these price-based policies will face similar difficulties by virtue of the large wealth effects they create.

The results also point to an important non-linear effect of these programs designed to improve nutrition. Such programs (again, almost regardless of their nature) are unlikely to significantly improve nutrition among subsistence households unless they effectively move them out of the subsistence zone. Programs that provide only small real wealth benefits allow subsistence zone households to get the same nutritional outcome using taste-preferred foods, and

\footnotetext{
${ }^{45}$ While calories are the most important nutrient, and thus the focus of most research, other nutrients such as protein are important as well. However, computing protein intake is difficult because the protein found in foods other than meat is generally "incomplete" (i.e., does not contain all 11 essential amino acids). Foods such as rice or wheat are deficient in lysine in particular, and must be complemented with legumes to make a complete protein. Preliminary computations based on amino acid content suggest protein intake follows a similar inverted-U pattern as calories in response to a staple price increase. Thus, while it may seem that the substitution away from the staple and towards meat is valuable because it increases protein, it appears the gain from increased meat consumption is not enough to offset the loss from the combined reduction of the staple and legumes.
} 
thus will have little impact on their nutrition. However, once the value of the benefits reaches a size where subsistence consumers move into the standard zone, households will begin to improve both taste and nutrition. Thus, programs that appear not to increase calorie intake or in fact cause it to decline (and which might therefore be at risk of being eliminated) could have a significant effect on these households if their benefits were increased. However, the same non-linearities have the opposite implications for households in the calorie-deprived zone. For these households, increasing the value of the benefits will improve calories only up to a point, after which some households will be in the subsistence zone and the calorie improvement will level off, and then decline. From an evaluation perspective, this leveling off or decline could make the average effect of a program appear much smaller and suggests the heterogeneous response must be taken into consideration. ${ }^{46}$ From a program targeting perspective, there is an equal challenge, as these non-linearities suggest it is important to tailor the size of the subsidy to the household's consumption zone. Thus, recognizing the heterogeneity of poor households is important for the design, evaluation and targeting of such programs.

However, it is also worth noting that the results present somewhat more positive news about household vulnerability. Policy makers are often concerned that households highly dependent on staple goods may experience nutrition declines when the prices of those goods increase, and a great number of programs worldwide are designed to protect against this very possibility. The results here suggest that in fact households in the subsistence zone are able to buffer caloric intake against such shocks quite well (unless the shocks are very large). However, there will still be a value in offering such assistance to households in the calorie-deprived zone, or perhaps even households in the subsistence zone (though the justification would have to be on general welfare, rather than nutritional, grounds).

\section{CONCLUSION}

We find strong, clear evidence of Giffen behavior among poor households in Hunan, China, and somewhat less robust evidence in Gansu. To the best of our knowledge, this is the first rigorous, real-world empirical evidence of Giffen behavior. It is ironic that despite a long

\footnotetext{
${ }^{46}$ In fact, the two effects could offset each other from an evaluation perspective; relatively small benefits improve nutrition among the calorie-deprived but decrease it among subsistence consumers, while larger benefits begin to reduce calories among the formerly calorie-deprived but increase them among the formerly subsistence consumers. Thus, the heterogeneous response could mask significant gains among subsets of consumers.
} 
search, in sometimes unusual settings, we found examples in the most widely consumed foods for the most populous nation in history. However, the examples were found exactly where theory would predict they should occur: impoverished (but not too impoverished) consumers, heavily dependent on a staple good, with limited substitution possibilities. And while our experiment focused on two areas of China, our framework and analysis suggest that Giffen behavior may not be rare at all. To begin, the socio-economic class we are studying -- the urban poor in China -- is extremely large, representing an estimated 90 million individuals. Thus, to the extent that our experiment is representative of that population, in terms of number of people, Giffen behavior is probably quite common. Second, our empirical approach to the issue differs in important ways from previous attempts to identify Giffen behavior. Earlier approaches focused on market-level price and quantity data, which for many reasons are unlikely to exhibit Giffen properties. Our approach uses individual-level data and focuses on parsing the data by an appropriate measure of wealth. These techniques have never been applied to other likely candidates for Giffen behavior. We believe there is nothing unusual or unique about the Chinese case; anecdotal evidence suggests that similar dietary patterns to those observed here are found among much of the world's poor (with staples including maize, millet, sorghum and cassava in addition to rice and wheat). ${ }^{47}$ Thus, it may be better to interpret our study as the first evidence of Giffen behavior rather than the only possible evidence. In fact, it is even possible that, if the right data were available, the claims by Marshall and Samuelson that bread and potatoes were Giffen would be verified.

Although, historically, the primary importance of the Giffen phenomenon has been pedagogical, we argue that such behavior has important implications for policy as well as for understanding household vulnerability and the consumption of the poor more broadly. Beyond that, we believe the Giffen effect serves a more fundamental role in economic theory. The neoclassical model of the consumer is one in which the consumer maximizes stable preferences subject to a budget constraint, and in recent years this model has come increasingly under attack. These objections run from the simplistic, "people don't maximize" arguments to the sophisticated criticisms found in psychology and behavioral economics. The possibility of Giffen behavior is a clear, complex, nuanced prediction of the neoclassical model. Where naïve intuition

\footnotetext{
${ }^{47}$ There is ample quantitative evidence of these patterns as well. For example, Deaton and Subramanian (1996) find that the poorest households in rural Maharashtra, India on average receive 53 percent of their calories from sorghum
} 
suggests that consumers should respond to a price increase by consuming less of the good in question, consumer theory suggests that a sophisticated consumer, mindful of the interplay between nutritional and budgetary concerns, might increase consumption. Further, the theory tells us exactly when and where we should expect to find Giffen behavior, and where we should not. To our knowledge, no other theory predicts the pattern of behavior implicit in the Giffen phenomenon, i.e., the sign of the price elasticity changing from negative to positive and back to negative as very poor consumers' wealth increases. Thus, while economists' failure to document Giffen behavior in the past has been interpreted as a criticism of the approach, our finding of Giffen behavior provides a type of vindication. Giffen behavior is predicted by the neoclassical model and no other. While psychological and behavioral theories help to account for some areas of economic behavior, in the case of the Giffen phenomenon, and of the consumption behavior of the extremely poor more generally, the standard model appears to be the right one.

\section{REFERENCES}

Baruch, Shmuel and Yakar Kannai (2001). "Inferior Goods, Giffen Goods, and Shochu." In G. Debreu, W. Neuefeind and W. Trockel (eds.), Economics Essays, A Festschrift for Werner Hildenbrand, Heidelberg, Springer-Verlag, 9-17.

Battalio, Raymond C., John H. Kagel, and Carl A. Kogut (1991). "Experimental Confirmation of the Existence of a Giffen Good," American Economic Review, 81(4) p. 961-70.

Boland, Lawrence A. (1977). "Giffen Goods, Market Prices and Testability," Australian Economic Papers, 16 (28). p 72-85.

Bopp, Anthony (1983). "The Demand for Kerosene: A Modern Giffen Good," Applied Economics, 15(4). p 459-468.

Chen, John-ren (1994). "The Effects of Land Reform on the Rice Sector and Economic Development in Taiwan”, World Development, Vol. 22, No.11, pp.1759-1770.

Deaton, Angus (1997). The Analysis of Household Surveys: A Microeconomic Approach to Development Policy. Baltimore, Maryland: The Johns Hopkins University Press.

-- and Shankar Subramanian (1996). "The Demand for Food and Calories," Journal of Political Economy, 104(1), p. 133-162.

DeGrandpre, R. J., Bickel, W. K., Rizvi, S. A., \& Hughes, J. R. (1993). "Effects of income on drug choice in humans." Journal of the Experimental Analysis of Behavior, 59, 483-500.

Dorfman, Robert, Paul A. Samuelson, and Robert M. Solow (1958). Linear Programming and Economic Analysis. McGraw Hill: New York.

Dougan, William R. (2002). "Giffen Goods and the Law of Demand," Journal of Political Economy, 90(4), p. 809-15.

Dwyer, Gerald P. and Cotton M. Lindsay (1984). "Robert Giffen and the Irish Potato," American Economic Review, 74(1), p. 188-192.

(and spend on average 20 percent of their total household budgets on this food). 
Friedman, Jed and James Levinsohn (2002). "The Distributional Impacts of Indonesia's Financial Crisis on Household Welfare: A "Rapid Response" Methodology." World Bank Economic Review, 16(3), p. 397-423.

Gilley, Otis and Gordon V. Karels (1991). "In Search of Giffen Behavior," Economic Inquiry, 29(1), p. 182-9.

Halbrendt, Catherine, Francis Tuan, Conrado Gempesaw and Dimphna Dolk-Etz (1994). "Rural Chinese Food Consumption: The Case of Guandong," American Journal of Agricultural Economics, 76, p. 794-99.

Jensen, Robert T. and Nolan Miller (2002). "Giffen Behavior in China: Evidence from the China Health and Nutrition Survey," Faculty Research Working Paper RWP02-014, John F. Kennedy School of Government, Harvard University.

Koenker, Roger (1977). "Was Bread Giffen? The Demand for Food in England Circa 1790," The Review of Economics and Statistics, 59(2), p. 225-229.

Marshall, Alfred (1895). Principles of Economics. Macmillan: London.

McDonough, Terrence and Joseph Eisenhauer (1995). "Sir Robert Giffen and the Great Potato Famine: A Discussion of the Role of a Legend in Neoclassical Economics," Journal of Economic Issues, 29(3), p. 747-759.

McKenzie, David (2002). “Are Tortillas a Giffen Good in Mexico?” Economics Bulletin, 15(1), p. 1-7.

Nachbar, John H. (1998). “The Last Word on Giffen Goods?” Economic Theory, 11, p. 403-12.

Ravallion, Martin (2007). "Geographic Inequality in a Decentralized Anti-Poverty Program: A CaseStudy of China," World Bank Policy Research Working Paper No. 4303.

Rosen, Sherwin (1999). "Potato Paradoxes," Journal of Political Economy, 107 (6), Part 2, p. S294-313.

Samuelson, Paul (1964). Economics. $5^{\text {th }}$ ed. New York: McGraw Hill.

Stigler, George (1947). "Notes on the History of the Giffen Paradox," Journal of Political Economy, 55(2), p. 152-156.

- - (1987). The Theory of Price, Fourth Edition. The Macmillan Company: New York.

Strauss, John and Duncan Thomas (1995). "Human Resources: Empirical Modeling of Household and Family Decisions," in Behrman, Jere R. and T.N. Srinivasan, eds., Handbook of Development Economics, Volume 3, Amsterdam: North-Holland.

Thomas, Duncan and John Strauss (1997). "Health and Wages: Evidence on Men and Women in Urban Brazil,” Journal of Econometrics, 77(1), p. 159-85. 
Table 1. Means and Standard Deviations of Key Variables

HUNAN

\begin{tabular}{lcccc} 
& Control & 0.1 yuan/jin subsidy & 0.2 yuan/jin subsidy & 0.3 yuan/jin subsidy \\
\cline { 2 - 5 } Family size & 2.8 & 2.9 & 3.0 & 2.7 \\
& {$[1.3]$} & {$[1.3]$} & {$[1.4]$} & {$[1.1]$} \\
\# of kids $(\leq 16)$ & 0.5 & 0.5 & 0.4 & 0.4 \\
& {$[0.68]$} & {$[0.6883]$} & {$[0.6687]$} & {$[0.61]$} \\
Female head & 0.34 & 0.37 & 0.37 & 0.40 \\
& {$[0.47]$} & {$[0.4844]$} & {$[0.4844]$} & {$[0.49]$} \\
Income per capita & 604 & 557 & 703 & 751 \\
& {$[1227]$} & {$[797]$} & {$[959]$} & {$[2451]$} \\
Expenditure per capita & 316 & 330 & 299 & 361 \\
& {$[252]$} & {$[316]$} & {$[290]$} & {$[483]$} \\
Calories per capita & 1767 & 1783 & 1817 & 1851 \\
& {$[628]$} & {$[588]$} & {$[549]$} & {$[601]$} \\
Rice per capita $(\mathrm{g})$ & 317 & 325 & 340 & 338 \\
& {$[122]$} & {$[129]$} & {$[128]$} & {$[120]$} \\
Meat per capita $(\mathrm{g})$ & 50.4 & 42.4 & $40.7^{*}$ & $52.8^{*}$ \\
& {$[81.6]$} & {$[61.0]$} & {$[59.2]$} & {$[70.3]$} \\
Rice calorie share & 0.639 & 0.636 & 0.645 & 0.642 \\
& {$[0.188]$} & {$[0.186]$} & {$[0.158]$} & {$[0.152]$} \\
Observations & 161 & 162 & 162 & 159 \\
& & \multicolumn{3}{|c}{}
\end{tabular}

Control $\quad 0.1$ yuan/jin subsidy $\quad 0.2$ yuan/jin subsidy $\quad 0.3$ yuan/jin subsidy

$\begin{array}{lcccc}\text { Family size } & 2.9 & 2.7 & 2.7 & 2.7 \\ & {[1.1]} & {[1.1]} & {[0.95]} & {[1.1]} \\ \text { \# of kids }(\leq 16) & 0.56 & 0.55 & 0.54 & 0.54 \\ & {[0.64]} & {[0.69]} & {[0.66]} & {[0.60]} \\ \text { Female head } & 0.44 & 0.40 & 0.44 & 0.44 \\ & {[0.50]} & {[0.49]} & {[0.50]} & {[0.50]} \\ \text { Income per capita } & 694 & 694 & 724 & 726 \\ & {[663]} & {[652]} & {[800]} & {[697]} \\ \text { Expenditure per capita } & 202 & 228 & 198 & 216 \\ & {[247]} & {[214]} & {[231]} & {[201]} \\ \text { Calories per capita } & 1737 & 1732 & 1716 & 1655 \\ & {[496]} & {[553]} & {[500]} & {[520]} \\ \text { Wheat per capita }(\mathrm{g}) & 352.6 & 353.4 & 340.7 & 328.7 \\ & {[132]} & {[147]} & {[136]} & {[120]} \\ \text { Meat per capita }(\mathrm{g}) & 13.9 & 9.7 & 13.5 & 13.6 \\ & {[30.9]} & {[23.8]} & {[33.7]} & {[31.1]} \\ \text { Wheat calorie share } & 0.691 & 0.691 & 0.678 & 0.680 \\ & {[0.176]} & {[0.172]} & {[0.181]} & {[0.165]} \\ \text { Observations } & 163 & 162 & 162 & 162\end{array}$

Notes: Standard deviations in brackets. All consumption figures are in grams per capita. Calorie share is the percent of total calories attributable to the particular food category. Income and expenditure per capita are in 2006 yuan $(\mathrm{Rmb}) .1$ jin $=500 \mathrm{~g} . *$ The only pair-wise difference that is statistically significant (at the 10 percent level) is meat per capita consumption in Hunan for the $0.3 y u a n / j i n$ vs. 0.2 yuan/jin groups. 
Table 2. Food Characteristics per Yuan

\begin{tabular}{|c|c|c|c|c|c|c|c|c|}
\hline & \multirow[b]{2}{*}{$\begin{array}{c}\text { Price } \\
\text { (Yuan/kg) }\end{array}$} & \multirow[b]{2}{*}{$\begin{array}{c}\text { Grams } \\
\text { per Yuan }\end{array}$} & \multicolumn{3}{|c|}{ HUNAN } & \multirow[b]{2}{*}{$\begin{array}{c}\text { Protein }(\mathrm{g}) \\
\text { Per Yuan }\end{array}$} & \multirow[b]{2}{*}{$\begin{array}{l}\text { Fat }(\mathrm{g}) \text { per } \\
\text { Gram }\end{array}$} & \multirow[b]{2}{*}{$\begin{array}{l}\text { Fat (g) pe } \\
\text { Yuan }\end{array}$} \\
\hline & & & $\begin{array}{l}\text { Calories } \\
\text { Per Gram }\end{array}$ & $\begin{array}{l}\text { Calories } \\
\text { Per Yuan }\end{array}$ & $\begin{array}{c}\text { Protein }(\mathrm{g}) \\
\text { Per Gram }\end{array}$ & & & \\
\hline Rice & 2.48 & 403 & 3.47 & 1399 & 0.08 & 32 & 0.01 & 2 \\
\hline Wheat & 2.82 & 355 & 3.44 & 1221 & 0.11 & 40 & 0.02 & 5 \\
\hline Pork & 12.60 & 79 & 3.95 & 313 & 0.13 & 10 & 0.37 & 29 \\
\hline Eggs & 9.32 & 107 & 1.37 & 147 & 0.13 & 14 & 0.09 & 10 \\
\hline Millet & 6.66 & 150 & 3.58 & 537 & 0.09 & 14 & 0.03 & 5 \\
\hline Cabbage & 1.60 & 625 & 0.23 & 141 & 0.02 & 11 & 0.01 & 3 \\
\hline \multirow[t]{4}{*}{ Bean Curd } & 2.38 & 420 & 0.57 & 239 & 0.07 & 29 & 0.03 & 11 \\
\hline & & BULK & & ENERGY & & PROTEIN & & TASTE \\
\hline & & & & $\underline{\text { GANSU }}$ & & & & \\
\hline & $\begin{array}{c}\text { Price } \\
\text { (Yuan } / \mathrm{kg} \text { ) }\end{array}$ & $\begin{array}{l}\text { Grams } \\
\text { per Yuan }\end{array}$ & $\begin{array}{l}\text { Calories } \\
\text { Per Gram }\end{array}$ & $\begin{array}{l}\text { Calories } \\
\text { Per Yuan }\end{array}$ & $\begin{array}{c}\text { Protein }(\mathrm{g}) \\
\text { Per Gram }\end{array}$ & $\begin{array}{c}\text { Protein }(\mathrm{g}) \\
\text { Per Yuan }\end{array}$ & $\begin{array}{l}\text { Fat }(\mathrm{g}) \text { per } \\
\text { Gram }\end{array}$ & $\begin{array}{l}\text { Fat }(\mathrm{g}) \text { per } \\
\text { Yuan }\end{array}$ \\
\hline Rice & 3.54 & 282 & 3.47 & 980 & 0.08 & 22 & 0.01 & 2 \\
\hline Wheat & 2.08 & 480 & 3.44 & 1655 & 0.11 & 54 & 0.02 & 7 \\
\hline Pork & 11.62 & 86 & 3.95 & 340 & 0.13 & 11 & 0.37 & 32 \\
\hline Eggs & 6.22 & 161 & 1.37 & 220 & 0.13 & 20 & 0.09 & 14 \\
\hline Millet & 3.24 & 308 & 3.58 & 1105 & 0.09 & 28 & 0.03 & 10 \\
\hline Cabbage & 1.3 & 769 & 0.23 & 173 & 0.02 & 14 & 0.01 & 4 \\
\hline \multirow[t]{2}{*}{ Bean Curd } & 2.54 & 394 & 0.57 & 224 & 0.07 & 27 & 0.03 & 10 \\
\hline & & BULK & & ENERGY & & PROTEIN & & TASTE \\
\hline
\end{tabular}

Notes: Rice: late, long-grain (wanxian); wheat: standard (Biaozhunfen); bean curd (nandoufu); cabbage (Dabaicai (xiaobaikou)); pork: lean and fatty (Zhurou (feishou)); Millet: foxtail (xioami); eggs: hen eggs (jidan). All quantities are in grams, all prices are in 2006 yuan $(\mathrm{Rmb})$ per kilogram. 
Table 3. Daily Consumption Per Capita and Calorie Shares for Food Categories

\begin{tabular}{|c|c|c|c|c|}
\hline & \multicolumn{2}{|c|}{ HUNAN } & \multicolumn{2}{|c|}{ GANSU } \\
\hline & Consumption $(\mathrm{g})$ & Calorie Share & Consumption $(\mathrm{g})$ & Calorie Share \\
\hline \multirow[t]{2}{*}{ Rice } & 330 & 0.64 & 35 & 0.07 \\
\hline & {$[125.4]$} & {$[0.17]$} & {$[69.5]$} & {$[0.13]$} \\
\hline \multirow[t]{2}{*}{ Wheat } & 42 & 0.08 & 344 & 0.69 \\
\hline & [60.2] & {$[0.12]$} & [134.3] & {$[0.17]$} \\
\hline \multirow[t]{2}{*}{ Other Cereals } & 1.5 & 0.00 & 4.2 & 0.01 \\
\hline & [21.3] & {$[0.022]$} & [24.2] & {$[0.050]$} \\
\hline \multirow[t]{2}{*}{ Vegetables and fruit } & 341 & 0.05 & 232 & 0.07 \\
\hline & [194.6] & {$[0.044]$} & [141.6] & {$[0.045]$} \\
\hline \multirow[t]{2}{*}{ Meat (incl. eggs) } & 47 & 0.07 & 13 & 0.01 \\
\hline & [68.6] & {$[0.11]$} & [30.1] & {$[0.037]$} \\
\hline \multirow[t]{2}{*}{ Pulses } & 62 & 0.02 & 36 & 0.02 \\
\hline & {$[102.3]$} & {$[0.043]$} & [68.1] & {$[0.056]$} \\
\hline \multirow[t]{2}{*}{ Dairy } & 1 & 0.00 & 19 & 0.01 \\
\hline & [7.4] & {$[0.0031]$} & {$[56.6]$} & {$[0.039]$} \\
\hline \multirow[t]{2}{*}{ Fats } & 26 & 0.13 & 23 & 0.13 \\
\hline & {$[20.4]$} & {$[0.095]$} & {$[16.3]$} & {$[0.090]$} \\
\hline \multirow[t]{2}{*}{ Calories } & 1805 & -- & 1710 & -- \\
\hline & [591.7] & & {$[517.4]$} & \\
\hline Observations & 644 & 644 & 649 & 649 \\
\hline
\end{tabular}


Table 4. Consumption Response to the Price Subsidy: Hunan

\begin{tabular}{|c|c|c|c|c|c|c|c|c|c|}
\hline & \multicolumn{7}{|c|}{$\begin{array}{l}\text { Dependent Variable: } \\
\% \Delta \text { Rice Consumption }\end{array}$} & \multicolumn{2}{|c|}{$\begin{array}{l}\text { Dependent Variable: } \\
\% \Delta \text { Meat Consumption }\end{array}$} \\
\hline & Full Sample & Full Sample & ISCS $\leq 0.80$ & ISCS $\leq 0.80$ & ISCS $>0.80$ & ISCS $>0.80$ & $\begin{array}{c}\text { ISCS } \\
0.60-0.80 \\
\end{array}$ & Full Sample & $\begin{array}{l}\text { Initial Intake } \\
>50 \mathrm{~g}\end{array}$ \\
\hline$\% \Delta$ Price(rice) & $\begin{array}{c}0.224 \\
(0.149)\end{array}$ & $\begin{array}{c}0.235^{*} \\
(0.140)\end{array}$ & $\begin{array}{c}0.451^{* * * 1} \\
(0.170)\end{array}$ & $\begin{array}{l}0.466^{* * *} \\
(0.159)\end{array}$ & $\begin{array}{l}-0.61^{* *} \\
(0.296)\end{array}$ & $\begin{array}{l}-0.585^{* *} \\
(0.262)\end{array}$ & $\begin{array}{l}0.640^{* * *} \\
(0.192)\end{array}$ & $\begin{array}{l}-0.325 \\
(0.472)\end{array}$ & $\begin{array}{l}-1.125^{*} \\
(0.625)\end{array}$ \\
\hline$\% \Delta$ Earned & & $\begin{array}{l}0.043^{* * *} \\
(0.014)\end{array}$ & & $\begin{array}{l}0.047^{* * *} \\
(0.016)\end{array}$ & & $\begin{array}{c}0.024 \\
(0.023)\end{array}$ & $\begin{array}{c}0.030 \\
(0.019)\end{array}$ & $\begin{array}{c}0.028 \\
(0.050)\end{array}$ & $\begin{array}{c}0.105 \\
(0.069)\end{array}$ \\
\hline$\% \Delta$ Unearned & & $\begin{array}{l}-0.044^{*} \\
(0.025)\end{array}$ & & $\begin{array}{l}-0.038 \\
(0.030)\end{array}$ & & $\begin{array}{l}-0.058 \\
(0.049)\end{array}$ & $\begin{array}{l}-0.053^{*} \\
(0.030)\end{array}$ & $\begin{array}{c}0.061 \\
(0.079)\end{array}$ & $\begin{array}{c}0.084 \\
(0.104)\end{array}$ \\
\hline$\% \Delta$ People & & $\begin{array}{l}0.89^{* * *} \\
(0.08)\end{array}$ & & $\begin{array}{l}0.83^{* * *} \\
(0.09)\end{array}$ & & $\begin{array}{l}1.16^{* * *} \\
(0.15)\end{array}$ & $\begin{array}{l}0.79^{* * *} \\
(0.14)\end{array}$ & $\begin{array}{l}-0.08 \\
(0.27)\end{array}$ & $\begin{array}{c}0.03 \\
(0.36)\end{array}$ \\
\hline Constant & & $\begin{array}{l}4.1^{* * *} \\
(1.0)\end{array}$ & & $\begin{array}{l}5.7^{* * *} \\
(1.1)\end{array}$ & & $\begin{array}{l}-1.8 \\
(1.7)\end{array}$ & $\begin{array}{l}0.8 \\
(1.3)\end{array}$ & $\begin{array}{c}-12.3^{* * *} \\
(3.1)\end{array}$ & $\begin{array}{c}-49.0^{* * *} \\
(3.7)\end{array}$ \\
\hline $\begin{array}{l}\text { Observations } \\
\mathrm{R}^{2}\end{array}$ & $\begin{array}{l}1258 \\
0.08\end{array}$ & $\begin{array}{l}1258 \\
0.19\end{array}$ & $\begin{array}{l}997 \\
0.09\end{array}$ & $\begin{array}{l}997 \\
0.20\end{array}$ & $\begin{array}{l}261 \\
0.15\end{array}$ & $\begin{array}{l}261 \\
0.33\end{array}$ & $\begin{array}{l}513 \\
0.24\end{array}$ & $\begin{array}{l}997 \\
0.09\end{array}$ & $\begin{array}{l}452 \\
0.28\end{array}$ \\
\hline
\end{tabular}


Table 5. Robustness of Results to Alternative Specifications: Hunan

\begin{tabular}{|c|c|c|c|c|c|c|c|c|c|c|c|c|c|}
\hline & (1) & (2) & (3) & (4) & (5) & (6) & (7) & (8) & (9) & (10) & (11) & (12) & (13) \\
\hline & \multicolumn{3}{|c|}{$\underline{\log -\log \text { Specification }}$} & \multicolumn{3}{|c|}{ Consumption Per Capita } & \multicolumn{3}{|c|}{ Individual Level Data } & \multicolumn{4}{|c|}{ Expenditure Per Capita Thresholds } \\
\hline & Full & $\leq 0.80$ & $>0.80$ & Full & $\leq 0.80$ & $>0.80$ & Full & $\leq 0.80$ & $>0.80$ & $\geq 2 \overline{5^{\text {th }}}$ & $<25^{\text {th }}$ & $\geq 15^{\text {th }}$ & $<15^{\text {th }}$ \\
\hline \multirow[t]{2}{*}{$\% \Delta$ Price(rice) } & 0.399 & $0.694^{* *}$ & $-0.718^{* *}$ & $0.762^{*}$ & $1.348^{* * *}$ & -1.348 & 0.233 & $0.384^{* *}$ & -0.223 & $0.286^{*}$ & 0.139 & $0.301^{* *}$ & -0.132 \\
\hline & $(0.254)$ & $(0.304)$ & $(0.294)$ & $(0.423)$ & $(0.476)$ & $(0.842)$ & $(0.144)$ & $(0.169)$ & $(0.225)$ & $(0.167)$ & $(0.238)$ & $(0.153)$ & $(0.288)$ \\
\hline \multirow[t]{2}{*}{$\% \Delta$ Earned } & $0.010^{* *}$ & 0.012 & 0.003 & $0.091^{* *}$ & $0.103^{* *}$ & 0.041 & $0.041^{* * *}$ & $0.046^{* * *}$ & 0.022 & $0.039^{* *}$ & $0.050^{* *}$ & $0.041^{* * *}$ & $0.054^{* *}$ \\
\hline & $(0.006)$ & $(0.007)$ & $(0.007)$ & $(0.043)$ & $(0.048)$ & $(0.083)$ & $(0.014)$ & $(0.016)$ & $(0.024)$ & $(0.017)$ & $(0.023)$ & $(0.015)$ & $(0.026)$ \\
\hline \multirow[t]{2}{*}{$\% \Delta$ Unearned } & $-0.031^{* *}$ & -0.030 & -0.038 & -0.107 & -0.066 & -0.225 & $-0.061^{* *}$ & -0.051 & $-0.082^{* *}$ & -0.037 & $-0.068^{*}$ & -0.033 & $-0.104^{* *}$ \\
\hline & $(0.018)$ & $(0.020)$ & $(0.025)$ & $(0.072)$ & $(0.080)$ & $(0.174)$ & $(0.027)$ & $(0.033)$ & $(0.041)$ & $(0.030)$ & $(0.040)$ & $(0.028)$ & $(0.046)$ \\
\hline \multirow[t]{2}{*}{$\% \Delta$ People } & $0.93^{* * *}$ & $0.85^{* * *}$ & $1.27^{* * *}$ & -0.28 & -0.55 & 0.89 & 0.01 & -0.08 & 0.27 & $0.89^{* * *}$ & $0.86^{* * *}$ & $0.87^{* * *}$ & $1.15^{* * *}$ \\
\hline & $(0.10)$ & $(0.10)$ & $(0.19)$ & $(0.32)$ & $(0.35)$ & $(0.57)$ & $(0.09)$ & $(0.10)$ & $(0.17)$ & $(0.10)$ & $(0.15)$ & $(0.09)$ & $(0.18)$ \\
\hline \multirow[t]{2}{*}{ Constant } & $0.04^{* *}$ & $0.05^{* *}$ & -0.003 & $11.9^{* * *}$ & $16.7^{* * *}$ & -5.3 & $5.3^{* * *}$ & $6.5^{* * *}$ & 0.8 & $4.3^{* * *}$ & $3.4^{*}$ & $3.9^{* * *}$ & $5.4^{* * *}$ \\
\hline & $(0.02)$ & $(0.02)$ & $(0.18)$ & $(3.0)$ & $(3.2)$ & $(6.0)$ & $(1.0)$ & $(1.2)$ & (1.7) & (1.1) & $(1.7)$ & $(1.1)$ & $(2.0)$ \\
\hline Observations & 1256 & 997 & 259 & 1258 & 997 & 261 & 2755 & 2191 & 564 & 971 & 287 & 1083 & 175 \\
\hline $\mathrm{R}^{2}$ & 0.11 & 0.11 & 0.31 & 0.09 & 0.11 & 0.18 & 0.05 & 0.06 & 0.10 & 0.18 & 0.31 & 0.19 & 0.35 \\
\hline
\end{tabular}

Notes: Regressions are county*time fixed-effect regressions where the dependent variable is the arc percent change in household rice consumption. Standard errors clustered at the household level. For columns $4-13: \% \Delta$ Price(rice) is the change in the subsidy, measured as a percentage of the average price of rice; $\% \Delta$ Earned is the arc percent change in the household earnings from work; \% $\% H H$ Unearned is the arc percent change in the household income from unearned sources (government payments, pensions, remittances, rent and interest from assets); and \% $\Delta$ People is the arc percent change in the number of people living in the household. For columns $1-3$, these percent changes result from using the log of the relevant variables. Initial Staple Calorie Share refers to the share of calories consumed as rice in the pre-intervention period. Initial Expenditure Per Capita refers to a household's percentile in the distribution of expenditure per capita in the pre-intervention period. *Significant at 10 percent level. **Significant at 5 percent level. ***Significant at 1 percent level. 
Table 6. Robustness to Alternative Staple Calorie Share Thresholds: Hunan

\begin{tabular}{|c|c|c|c|c|c|c|c|c|c|c|}
\hline & (1) & $(2)$ & (3) & (4) & $(5)$ & $(6)$ & $(7)$ & (8) & $(9)$ & $(10)$ \\
\hline & $\leq 0.70$ & $\leq 0.75$ & $\leq 0.80$ & $\leq 0.85$ & $\leq 0.90$ & $>0.70$ & $>0.75$ & $>0.80$ & $>0.85$ & $>0.90$ \\
\hline \multirow[t]{2}{*}{$\% \Delta$ Price(rice) } & $0.362^{* *}$ & $0.461^{* * *}$ & $0.466^{* * *}$ & $0.382^{* * *}$ & $0.270^{*}$ & 0.004 & -0.331 & $-0.585^{* *}$ & $-0.934^{*}$ & -0.617 \\
\hline & $(0.184)$ & $(0.174)$ & $(0.159)$ & $(0.145)$ & $(0.143)$ & $(0.203)$ & $(0.207)$ & $(0.262)$ & $(0.471)$ & $(0.681)$ \\
\hline \multirow[t]{2}{*}{$\% \Delta$ Earned } & $0.052^{* * *}$ & $0.049^{* * *}$ & $0.047^{* * *}$ & $0.044^{* * *}$ & $0.043^{* * *}$ & 0.028 & $0.028^{*}$ & 0.024 & 0.027 & 0.094 \\
\hline & $(0.019)$ & $(0.018)$ & $(0.016)$ & $(0.015)$ & $(0.014)$ & $(0.018)$ & $(0.017)$ & $(0.023)$ & $(0.035)$ & $(0.072)$ \\
\hline \multirow[t]{2}{*}{$\% \Delta$ Unearned } & -0.007 & -0.027 & -0.038 & -0.041 & $-0.044^{*}$ & $-0.093^{* *}$ & $-0.076^{*}$ & -0.058 & 0.001 & -0.036 \\
\hline & $(0.034)$ & $(0.031)$ & $(0.030)$ & $(0.027)$ & $(0.026)$ & $(0.037)$ & $(0.044)$ & $(0.049)$ & $(0.085)$ & $(0.154)$ \\
\hline \multirow[t]{2}{*}{$\% \Delta$ People } & $0.77^{* * *}$ & $0.79^{* * *}$ & $0.83^{* * *}$ & $0.87^{* * *}$ & $0.87^{* * *}$ & $1.13^{* * *}$ & $1.17^{* * *}$ & $1.16^{* * *}$ & $1.03^{* * *}$ & $1.35^{* * *}$ \\
\hline & $(0.11)$ & $(0.10)$ & $(0.09)$ & $(0.09)$ & $(0.09)$ & $(0.10)$ & $(0.12)$ & $(0.15)$ & $(0.26)$ & $(0.22)$ \\
\hline \multirow[t]{2}{*}{ Constant } & $7.4^{* * *}$ & $6.1^{* * *}$ & $5.7^{* * *}$ & $4.8^{* * *}$ & $4.3^{* * *}$ & -0.9 & -0.3 & -1.8 & -1.3 & 2.8 \\
\hline & $(1.3)$ & $(1.2)$ & $(1.1)$ & $(1.1)$ & $(1.0)$ & $(1.3)$ & $(1.4)$ & $(1.7)$ & $(2.3)$ & $(4.0)$ \\
\hline Observations & 777 & 883 & 997 & 1116 & 1196 & 481 & 375 & 261 & 142 & 62 \\
\hline $\mathrm{R}^{2}$ & 0.20 & 0.19 & 0.20 & 0.20 & 0.19 & 0.30 & 0.34 & 0.33 & 0.31 & 0.49 \\
\hline
\end{tabular}

Notes: Regressions are county*time fixed-effect regressions where the dependent variable is the arc percent change in household rice consumption. Standard errors clustered at the household level. $\% \Delta$ Price(rice) is the change in the subsidy, measured as a percentage of the average price of rice. $\% \Delta$ Earned is the arc percent change in the household earnings from work; $\% \Delta H H$ Unearned is the arc percent change in the household income from unearned sources (government payments, pensions, remittances, rent and interest from assets); \% $\%$ People is the arc percent change in the number of people living in the household. Initial Staple Calorie Share refers to the share of calories consumed as rice in the pre-intervention period. *Significant at 10 percent level. **Significant at 5 percent level. ***Significant at 1 percent level. 
Table 7. Consumption Response to the Subsidy: Gansu

\begin{tabular}{|c|c|c|c|c|c|c|c|c|c|c|c|}
\hline & $\begin{array}{c}(1) \\
\text { Full }\end{array}$ & (2) & (3) & (4) & (5) & (6) & (7) & $(8)$ & (9) & $(10)$ & (11) \\
\hline & Sample & $\leq 0.70$ & $>0.70$ & $\leq 0.55$ & $\leq 0.60$ & $\leq 0.65$ & $\leq 0.75$ & $\leq 0.80$ & $\leq 0.85$ & $\leq 0.90$ & $0.40-0.60$ \\
\hline$\% \Delta$ Price(wheat) & $\begin{array}{l}-0.353 \\
(0.258)\end{array}$ & $\begin{array}{c}0.024 \\
(0.366)\end{array}$ & $\begin{array}{l}-0.825^{* *} \\
(0.357)\end{array}$ & $\begin{array}{l}-0.245 \\
(0.453)\end{array}$ & $\begin{array}{c}0.309 \\
(0.452)\end{array}$ & $\begin{array}{c}0.128 \\
(0.414)\end{array}$ & $\begin{array}{c}0.009 \\
(0.326)\end{array}$ & $\begin{array}{l}-0.280 \\
(0.302)\end{array}$ & $\begin{array}{l}-0.321 \\
(0.283)\end{array}$ & $\begin{array}{l}-0.356 \\
(0.268)\end{array}$ & $\begin{array}{c}1.065^{*} \\
(0.557)\end{array}$ \\
\hline$\% \Delta$ Earned & $\begin{array}{l}0.079^{* *} \\
(0.036)\end{array}$ & $\begin{array}{c}0.098^{*} \\
(0.052)\end{array}$ & $\begin{array}{c}0.041 \\
(0.049)\end{array}$ & $\begin{array}{l}-0.048 \\
(0.065)\end{array}$ & $\begin{array}{c}0.023 \\
(0.062)\end{array}$ & $\begin{array}{c}0.064 \\
(0.057)\end{array}$ & $\begin{array}{l}0.124^{* * *} \\
(0.045)\end{array}$ & $\begin{array}{l}0.107^{* *} \\
(0.042)\end{array}$ & $\begin{array}{l}0.100^{* *} \\
(0.040)\end{array}$ & $\begin{array}{l}0.103^{* * *} \\
(0.038)\end{array}$ & $\begin{array}{c}0.063 \\
(0.074)\end{array}$ \\
\hline$\% \Delta$ Unearned & $\begin{array}{l}-0.017 \\
(0.092)\end{array}$ & $\begin{array}{c}-0.048 \\
(0.129)\end{array}$ & $\begin{array}{c}0.035 \\
(0.127)\end{array}$ & $\begin{array}{c}0.023 \\
(0.189)\end{array}$ & $\begin{array}{c}0.045 \\
(0.173)\end{array}$ & $\begin{array}{l}-0.007 \\
(0.141)\end{array}$ & $\begin{array}{c}0.005 \\
(0.112)\end{array}$ & $\begin{array}{c}0.063 \\
(0.105)\end{array}$ & $\begin{array}{c}0.034 \\
(0.102)\end{array}$ & $\begin{array}{c}0.009 \\
(0.093)\end{array}$ & $\begin{array}{c}0.189 \\
(0.181)\end{array}$ \\
\hline$\% \Delta$ People & $\begin{array}{l}0.58^{* * *} \\
(0.22)\end{array}$ & $\begin{array}{c}0.34 \\
(0.30)\end{array}$ & $\begin{array}{l}0.80^{* * *} \\
(0.25)\end{array}$ & $\begin{array}{c}0.18 \\
(0.41)\end{array}$ & $\begin{array}{c}0.25 \\
(0.34)\end{array}$ & $\begin{array}{c}0.24 \\
(0.32)\end{array}$ & $\begin{array}{c}0.40 \\
(0.27)\end{array}$ & $\begin{array}{c}0.42^{*} \\
(0.25)\end{array}$ & $\begin{array}{c}0.42^{*} \\
(0.23)\end{array}$ & $\begin{array}{l}0.53^{* *} \\
(0.22)\end{array}$ & $\begin{array}{c}0.11 \\
(0.32)\end{array}$ \\
\hline Constant & $\begin{array}{c}-26.1^{* * *} \\
(2.3)\end{array}$ & $\begin{array}{c}-20.8^{* * *} \\
(3.3)\end{array}$ & $\begin{array}{c}-32.8^{* * * *} \\
(2.9)\end{array}$ & $\begin{array}{c}-18.7^{* * *} \\
(4.5)\end{array}$ & $\begin{array}{c}-19.5^{* * *} \\
(4.1)\end{array}$ & $\begin{array}{c}-20.3^{* * *} \\
(3.7)\end{array}$ & $\begin{array}{c}-22.9^{* * *} \\
(3.0)\end{array}$ & $\begin{array}{c}-23.3^{* * *} \\
(2.7)\end{array}$ & $\begin{array}{c}-25.8^{* * *} \\
(2.6)\end{array}$ & $\begin{array}{c}-25.7^{* * *} \\
(2.4)\end{array}$ & $\begin{array}{c}-31.6^{* * *} \\
(4.4)\end{array}$ \\
\hline Observations & 1269 & 687 & 582 & 406 & 478 & 563 & 843 & 995 & 1107 & 1199 & 266 \\
\hline $\mathrm{R}^{2}$ & 0.08 & 0.11 & 0.09 & 0.17 & 0.14 & 0.12 & 0.09 & 0.10 & 0.08 & 0.08 & 0.24 \\
\hline
\end{tabular}

*time fixed-effect regressions where the dependent variable is the arc percent change in household rice consumption errors clustered at the household level. \% $\%$ Price(wheat) is the change in the subsidy, measured as a percentage of the average price of wheat. $\% \Delta$ Earned is the arc percent change in the household earnings from work; \% $\Delta \mathrm{HH}$ Unearned is the arc percent change in the household income from unearned sources (government payments, pensions, remittances, rent and interest from assets); \% $\Delta$ People is the arc percent change in the number of people living in the household. Initial Staple Calorie Share refers to the share of calories consumed as wheat (excluding purchased wheat foods such as noodles or bread) in the pre-intervention period.

*Significant at 10 percent level. **Significant at 5 percent level. ***Significant at 1 percent level. 
Table 8. Refinements of Consumption Response: Gansu

(1)

\begin{tabular}{cc} 
Consume $>50 \mathrm{~g}$ meat & Consume $<50 \mathrm{~g}$ Substitute Wheat \\
\hline $1.327^{*}$ & $1.106^{*}$ \\
$(0.701)$ & $(0.566)$ \\
$0.139^{*}$ & $0.156^{*}$ \\
$(0.076)$ & $(0.080)$ \\
0.059 & -0.056 \\
$(0.147)$ & $(0.172)$ \\
$1.70^{* * *}$ & 0.45 \\
$(0.23)$ & $(0.29)$ \\
0.82 & $-26.8^{* * *}$ \\
$(5.1)$ & $(5.5)$ \\
& \\
107 & 247 \\
0.33 & 0.22 \\
\hline
\end{tabular}

0.33

)

$\% \Delta$ Price(wheat)

$\% \Delta$ Earned

$\% \Delta$ Unearned

$\% \Delta$ People

Constant

) (2) 


\section{APPENDIX I. UNDERSTANDING GIFFEN BEHAVIOR}

Traditionally, the possibility of Giffen behavior has been motivated by an argument similar to Marshall's. We will argue that the need to maintain subsistence consumption is the critical factor leading to Giffen behavior, drawing connections between Marshall's verbal argument, two mathematical models of the situation, and the graphical analysis found in microeconomics textbooks. Although much of what follows in this section has previously appeared elsewhere, we believe that this analysis provides a useful synthesis of theoretical approaches to the Giffen phenomenon.

\section{Appendix I.A. The Characteristic-preference Model}

We consider very poor consumers whose behavior is driven by the need to achieve a subsistence calorie intake. Following Lancaster (1966), rather than having preferences over the foods themselves, we model consumers as having preferences over two fundamental characteristics of foods: calories, $c$, and taste, $t$, where taste is meant to capture the non-nutritive aspects of food. For expositional ease, we assume there are only two foods, a basic good, $b$, such as rice, and a fancy good, $f$, such as meat. Let $\left(c_{b}, t_{b}\right)$ and $\left(c_{f}, t_{f}\right)$ denote the calories and taste provided by a unit of the basic and fancy goods, respectively. Let $p>0$ denote the price of the basic good and normalize the price of the fancy good to 1. Spending one yuan (or Rmb, the Chinese unit of currency) on the fancy good provides more taste but fewer calories than spending a yuan on the basic good, i.e., $c_{f}<c_{b} / p$ and $t_{f}>t_{b} / p$.

The consumer's first priority is achieving subsistence calorie intake, which we denote by $c^{*}$. Once the consumer achieves subsistence, he attempts to maximize the taste of the foods he eats. ${ }^{48}$ Since sufficiently impoverished consumers prioritize calories over taste, we begin by considering a consumer whose objective is to maximize taste subject to budget and subsistence constraints; later we allow for more general preferences. Let $w>0$ be the consumer's wealth, and let $b$ and $f$ denote the units consumed of the basic and fancy goods, respectively. The consumer chooses $b$ and $f$ to maximize $t_{b} b+t_{f} f$ subject to the budget constraint, $p b+f \leq w$, and the subsistence constraint, $c_{b} b+c_{f} f \geq c^{*}$.

\footnotetext{
${ }^{48}$ A more general constraint on minimum nutritional requirements behaves similarly.
} 
Figure A1 illustrates the consumer's problem. Each point in this "characteristic space" is the calorie-taste outcome arising from a particular combination of the basic and fancy goods. Points $\mathrm{F}=\left(c_{f} w, t_{f} w\right)$ and $\mathrm{B}=\left(c_{b} w / p, t_{b} w / p\right)$ represent the calorie-taste bundles resulting from the consumer spending all their wealth on the fancy and basic goods, respectively. The set of affordable calorie-taste bundles is given by the convex hull of these two points and the origin, and the set of points where the consumer spends his entire wealth is the line segment FB. When the consumer's wealth is sufficiently high (i.e., point F lies beyond the subsistence constraint) as in panel A, the consumer can afford to get his calories exclusively from the fancy good. The solution to the consumer's problem is in this case point $\mathrm{F}$.
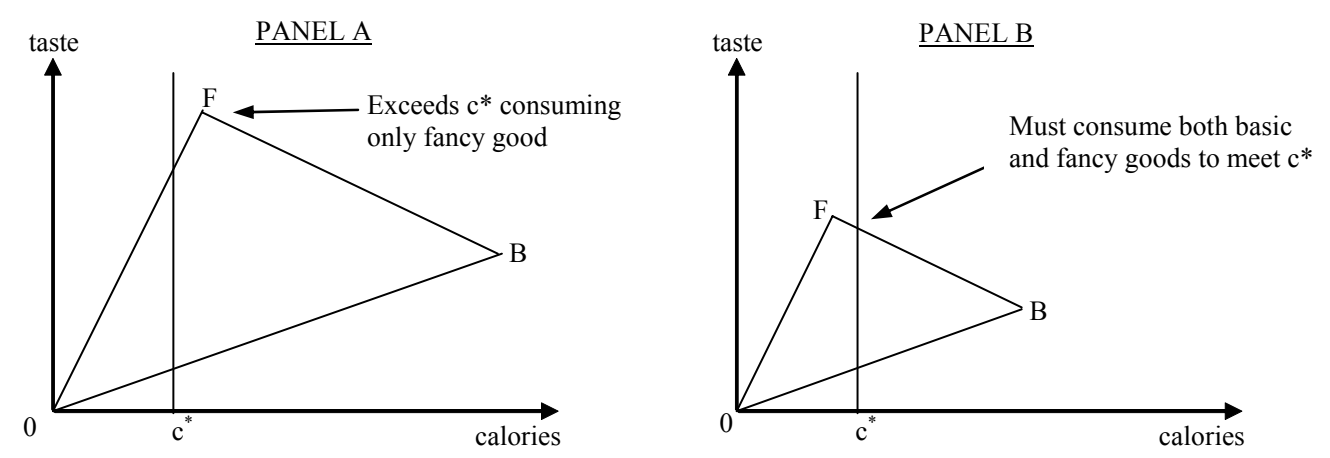

Figure A1: The consumer's problem with non-binding (Panel A) and binding (Panel B) calorie constraint.

If the consumer cannot achieve $c^{*}$ calories by consuming only the fancy good (i.e., $c_{f} w<$ $c^{*}$ ), as in panel $\mathrm{B}$, the solution to the consumer's problem lies at the intersection of the calorie constraint and the budget constraint FB. Thus, the consumer's demanded bundle is $\left(b^{*}, f^{*}\right)$, where $b^{*}=\left(c^{*}-c_{f} w\right) /\left(c_{b}-c_{f} p\right)$ and $f^{*}=\left(w c_{b}-p c^{*}\right) /\left(c_{b}-c_{f} p\right)$. To see that the basic good is Giffen, note that $\partial b^{*} / \partial p=c_{f}\left(c^{*}-c_{f} w\right) /\left(c_{f} p-c_{b}\right)^{2}>0$. A price increase leads to increased consumption of the basic good. This can also be seen graphically in figure A2. Here, we overlay vectors representing consumption of the basic and fancy goods; the slopes of these vectors reflect the calorie-taste combination for each good (they are therefore parallel to line segments $0 \mathrm{~F}$ and $0 \mathrm{~B}$, which reflect choosing only the fancy and only the basic goods, respectively). Panel A shows the initial consumption choices for a consumer who is unable to achieve subsistence calories by consuming only the fancy good. Panel B depicts the impact of an increase in the price of the basic good, which shifts the consumer's budget line from FB to FB'. Note that the vector $b$ ', 
which depicts consumption of the basic good at the higher price, is longer than $b^{*}$, which depicts consumption at the original price. Thus an increase in the basic good's price increases its consumption, i.e., the consumer exhibits Giffen behavior.

In our simple model we have assumed that the consumer maximizes taste subject to a calorie constraint. However, the qualitative features remain unchanged for more general preferences, provided that utility increases in taste and the minimum calorie constraint binds, as it will for a sufficiently impoverished consumer. ${ }^{49}$
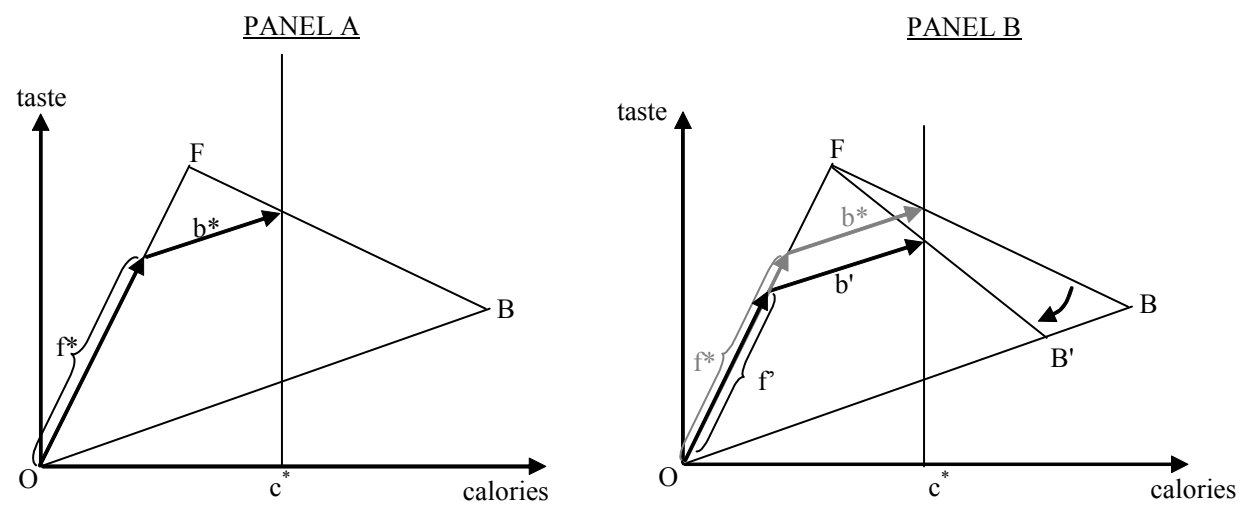

Figure A2: The response to a change in the price of the basic good (given a binding calorie constraint)

\section{Appendix I.B. The Gilley - Karels Model}

Gilley and Karels (1991) and Van Marrewijk and van Bergeijk (1990) study Giffen behavior in the context of the neoclassical model with an additional subsistence constraint. The consumer's utility maximization problem is to choose $b$ and $f$ to maximize $\mathrm{u}(b, f)$ subject to the same calorie and budget constraints as above, $c_{b} b+c_{f} f \geq c^{*}$ and $p b+f \leq w$, where $\mathrm{u}(b, f)$ is the consumer's utility function, assumed to be strictly increasing and strictly quasiconcave on all ( $b$, f) that satisfy the subsistence constraint. All other notation is unchanged.

Our first task is to translate figure A2 into the ordinary commodity space. Since $c_{b} / p>c_{f}$, the subsistence constraint is steeper than the budget constraint when $b$ is plotted on the horizontal axis, as in figure A3, panel A. The set of feasible consumption bundles is the shaded area above the subsistence constraint (dotted) and below the budget constraint (solid). Panel B depicts two

\footnotetext{
${ }^{49}$ The argument is essentially the same as the one presented at the end of Appendix Section I.B. Lipsey and Rosenbluth (1971) show in the context of the Lancaster (1966) model that Giffen behavior may be more likely than originally believed, even when the consumer is not subject to a minimum calorie constraint.
} 
possible budget sets for the consumer. In the first, the consumer has relatively high wealth $w_{1}$, and the consumer's subsistence constraint does not bind at the optimal consumption bundle, $x_{1}$. In this case, which is the standard case, the consumer's demanded bundle is the point of tangency between his utility isoquants and the budget constraint. However, as wealth decreases it becomes increasingly likely that the subsistence constraint binds at an optimum. In Panel B, wealth level $w_{0}$ corresponds to one such case. In this case, the highest utility bundle that satisfies both constraints lies on the intersection of the budget and subsistence constraints, just as it did in the characteristic-preference model. Thus the consumer demands bundle $x_{0}=\left(b^{*}, f^{*}\right)$, where $b^{*}$ and $f^{*}$ are as in the previous section. Since the consumer's demand is the same as in the characteristic-preference version of the problem, once again the basic good is Giffen.
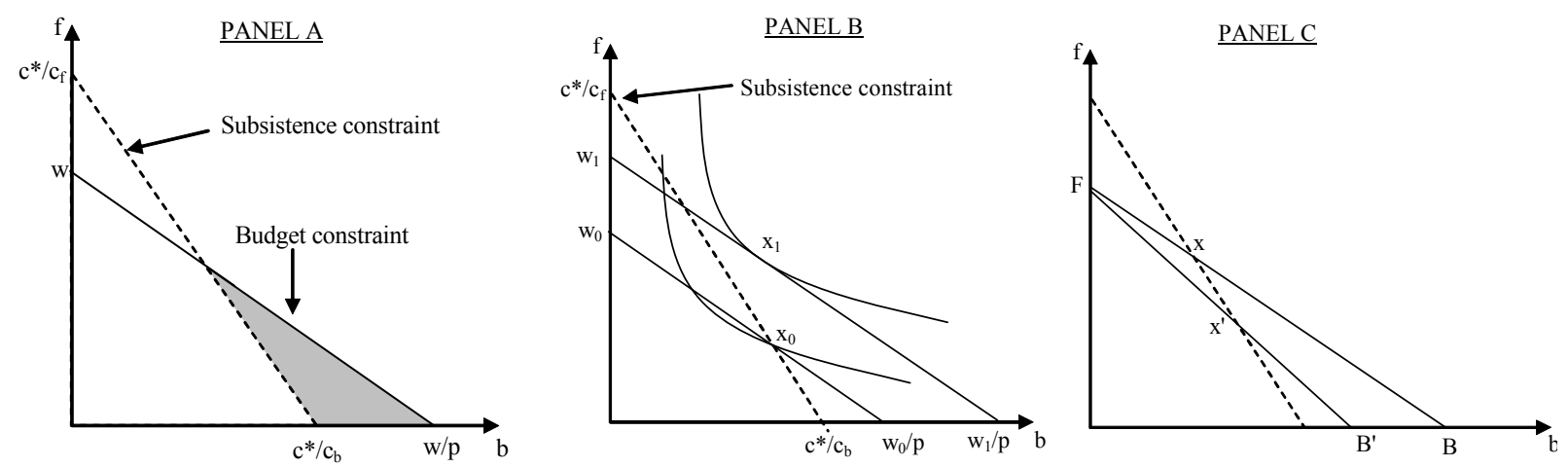

Figure A3: Giffen Behavior in the Gilley-Karels Model.

To see the consumer's reaction to a price increase graphically, consider panel C, which presents the price increase from $p$ to $p^{\prime}$ shown in panel $\mathrm{B}$ of figure $\mathrm{A} 2$. At price $p$, the budget constraint is line $\mathrm{FB}$, where $\mathrm{F}=(0, w)$ and $\mathrm{B}=(w / p, 0)$, and the consumer demands bundle $x$. The price increase to $p^{\prime}$ pivots the budget constraint clockwise to line $\mathrm{FB}^{\prime}\left(\mathrm{B}^{\prime}=\left(w / p^{\prime}, 0\right)\right)$ and moves the intersection of the budget and subsistence constraints to point $x^{\prime}$. Whichever bundle the consumer demands, it must lay on the new budget line between points $x^{\prime}$ and $\mathrm{B}^{\prime}$. However, any such point involves consuming more of the basic good, i.e., Giffen behavior.

\section{Appendix I.C. The Graphical (Textbook) Approach}

Approaches such as those presented above have been criticized on the grounds that consumer theory posits consumers who maximize preferences subject to a budget constraint. Any need for subsistence should therefore be built into the consumer's preferences (Wichers 
1994). In this section we present the textbook explanation of the Giffen phenomenon and argue that implicit in the shape of the indifference curves needed to account for Giffen behavior is a subsistence motive.

The standard pedagogical tool of intermediate microeconomics for explaining the Giffen phenomenon involves a graphical explanation. However, the indifference map needed to induce Giffen behavior is not standard. For example, typical, Cobb-Douglas indifference curves cannot generate Giffen behavior. In the typical presentation, the indifference curves used to illustrate Giffen behavior appear to "fan out," becoming closer together as you move to the northwest, as depicted in figure A4, panel A, where demand for the basic good increases as the price of the basic good increases. ${ }^{50}$
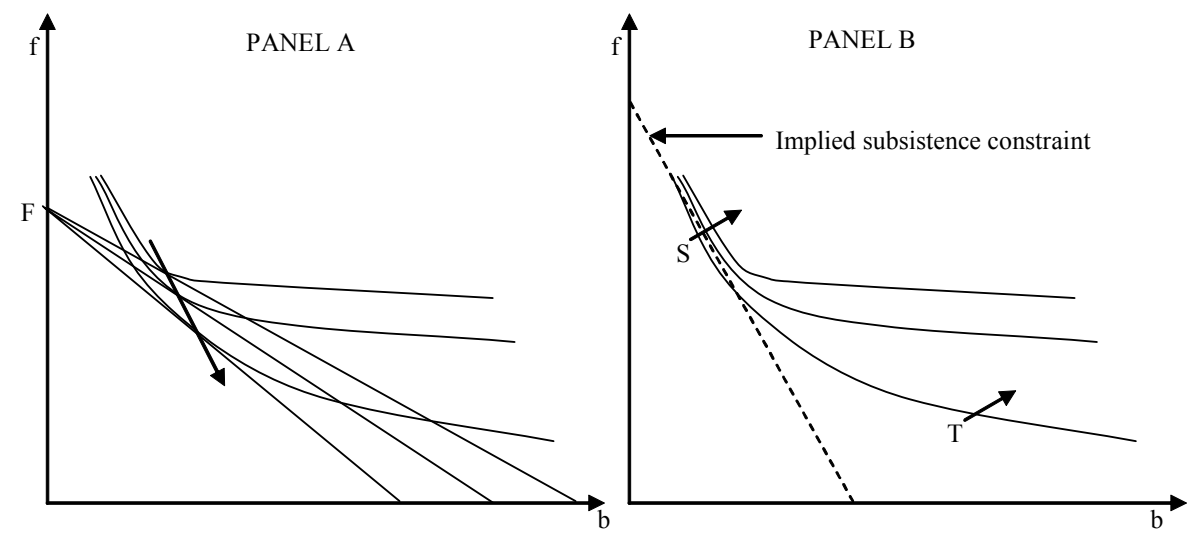

Figure A4: The Textbook Approach to Giffen Behavior

The link between the graphical presentation and the subsistence-constraint models is found in the shape of the indifference curves used to induce Giffen behavior. Consider figure A4, panel B, which isolates the indifference curves from panel A. Notice that because of the shape of the indifference curves, the consumer's utility increases more steeply when moving perpendicular to the dotted line than when moving parallel to it, and that utility also increases more steeply near the dotted line (point S) than above it (point T). Because utility increases rapidly perpendicular to the dotted line, the consumer will behave as if he faces a constraint to choose, whenever possible, a consumption bundle laying to the northeast of this line. It is, in effect, an implied subsistence constraint; thus the subsistence motive underlies even the standard pedagogical treatment of the Giffen phenomenon.

\footnotetext{
${ }^{50}$ Spiegel (1994) constructs a utility function that leads to Giffen behavior whose isoquants exhibit this shape.
} 
Thus, despite ostensibly different approaches, the intuition underlying all four motivations for Giffen behavior is the same. Poor consumers with few substitution possibilities facing a real or implied subsistence constraint will be forced, following an increase in the price of a basic good, to consume more of the cheapest source of calories available and less of other goods. As Gilley and Karels (1991, p.181) note, this suggests that "the most likely place [to find Giffen behavior] would be among the very poor, consuming a few staples, with limited substitution possibilities."

While these factors make detecting Giffen behavior more likely, there is one additional factor that must be considered. The mechanics of substitution accompanying Giffen behavior involve the consumer decreasing consumption of more desirable foods such as meat in order to increase consumption of the staple. However, extremely impoverished consumers may be so poor that they cannot afford to consume any of the fancy good. In this case, even if the price of the basic good goes up, Giffen behavior is not possible since there is no good whose consumption can be reduced to fund increased purchases of the basic good. Thus, while consumers must be poor, they cannot be too poor.

In light of this, the consumer's preferences can be thought of as falling into three distinct zones, as illustrated in figure A5. In panel A, the outer set of indifference curves correspond to the standard case, where the consumer's calorie intake is well above subsistence. Over this range the consumer trades off between calories and taste (and thus between the basic and fancy goods) in an ordinary way, and thus in panel B they respond to an increase in the price of the basic good by decreasing consumption of that good. The middle group of indifference curves corresponds to the range of consumption bundles over which the consumer crosses from malnutrition into nutritional stability. Over this range, the consumer is willing to sacrifice a great deal of taste (and thus the fancy good) in order to maintain calories; thus in panel B, they respond to an increase in the price of the basic good by consuming more of it, i.e., they exhibit Giffen behavior. Finally, in the inner-most, calorie-deprived zone, the consumer is struggling to achieve subsistence calorie intake, and therefore values increases in calories almost exclusively. Further, they may be using their entire budget on only the basic good, and thus as seen in panel B, they have no choice but to respond to a staple price increase by consuming less of it. 

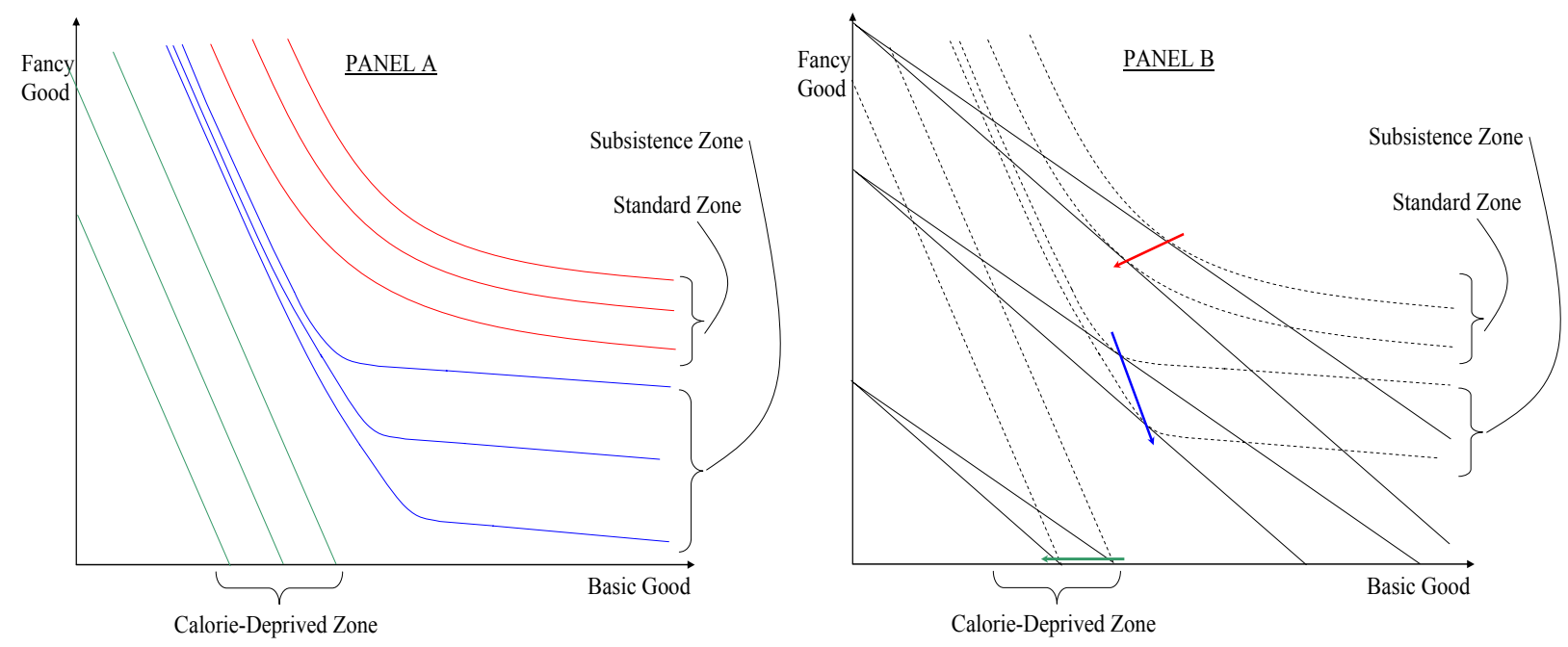

Figure A5. The Different Zones of Consumer Preferences

\section{APPENDIX REFERENCES}

Gilley, Otis and Gordon V. Karels (1991). "In Search of Giffen Behavior," Economic Inquiry, 29(1), p. $182-9$.

Lancaster, Kelvin J (1966). "A New Approach to Consumer Theory," Journal of Political Economy, 74(2), p. 132-157.

Lipsey, Richard G. and Gideon Rosenbluth (1971). "A Contribution to the New Theory of Demand: A Rehabilitation of the Giffen Good," Canadian Journal of Economics, 4(2), p. 131-163.

Spiegel, Uriel (1994) "The Case of a 'Giffen Good'," Journal of Economic Education, c, p. 137-47. van Marrewijk, Charles and Peter A.G. van Bergeijk (1990). "Giffen Goods and the Subsistence Level," History of Political Economy, 22(1), p. 145-8.

Wichers, Robert (1994) "In Search of Giffen Behavior: Comment," Economic Inquiry, 32, p. 166-167. 


\section{APPENDIX II: THE MINIMUM COST DIET AND THE STAPLE CALORIE SHARE}

Individual requirements for calories and essential amino acids vary a great deal and depend on a range of characteristics. To investigate the extent to which it might be possible to judge whether a particular person was meeting their essential nutritional needs, we solved a simplified version of the "diet problem," i.e., minimizing the cost of achieving certain nutritional requirements. To capture the importance of complete protein sources, using information from the National Research Council we imposed intake requirements for calories and 11 amino acids. ${ }^{\mathrm{A} 1} \mathrm{We}$ considered diets consisting of rice and bean curd in Hunan, and wheat flour and bean curd in Gansu. In both provinces, the staple is the cheapest source of calories, but it is relatively deficient in the essential amino acid lysine. Complementing cereal grains with legumes such as in bean curd is typically the cheapest way to ensure that a person receives all essential amino acids. Typically, only small amounts of bean curd are needed to complete the protein.

Nutritional content information was taken from the USDA National Nutrient Database for Standard Reference (the Chinese food tables used in the paper do not contain information on amino acid content of foods). ${ }^{\mathrm{A} 2}$ Calorie requirements are computed using the Estimated Energy Requirement equations from the Institute of Medicine. ${ }^{\mathrm{A} 3}$ In order to capture the realities of cooking technology, we assume that households receive $13 \%$ of their calories from fats, in this case in the form of cooking oil. In most cases this implies consumption of less than one tablespoon of oil per day.

We considered a number of different representative "people" of both sexes with a range of different height, weight, and activity level specifications ("V" denotes very active, "A" denotes active, "L" denotes less active, and "S" denotes sedentary). Scenarios G - J are chosen with typical heights for Chinese men and women who are slightly underweight or normal weight (by body mass index). For each person, we solved for the minimum-cost diet that satisfies the nutritional requirements for calories and each of the essential amino acids. In all cases, the calorie and lysine constraints bind and determine the solution. Hence to conserve space we do not report the other amino acid requirements.

The results of this exercise show wide variability in both caloric requirements and the cost of the least-cost diet (see table below). Daily calories required and the least-cost diet range from 1351 calories and 1.15 yuan/day in Gansu (1.21 in Hunan) for a sedentary elderly woman (scenario E) to 4264 calories and 2.69 yuan/day in Gansu (2.91 in Hunan) for an active young man (scenario A). Thus the calorie

\footnotetext{
${ }^{\text {A1 }}$ National Research Council, Dietary Reference Intakes for Energy, Carbohydrates, Fiber, Fat, Fatty Acids, Cholesterol, Protein, And Amino Acids (Dietary Reference Intakes), National Academies Press, Washington DC, 2005.

${ }_{\text {A2 }}$ USDA National Nutrient Database for Standard Reference, http://www.nal.usda.gov/fnic/foodcomp/search/.

${ }^{\text {A3 }}$ Gerrior, S. et al., "An Easy Approach to Calculating Estimated Energy Requirements," Preventing Chronic Diesase, 2006, October; 3(4): A129.
} 
requirements and income requirements necessary to be in good nutrition are both highly variable and highly sensitive to the underlying characteristics of the person under discussion.

We also report the proportion of calories from the staple for each scenario. The staple calorie share in the least-cost diet, while variable, is significantly less variable than either total calories or cost, ranging from 0.79 to 0.86 in Hunan and 0.78 to 0.85 in Gansu. While this is the staple calorie share associated with the least-cost diet, we are interested in those who have more than enough money, and thus will not purchase the least-cost diet. Since wealthier people will tend to get a greater proportion of their calories from non-staple sources, this suggests a reasonable cut-off of somewhere around 0.8 . We expect that people who get less than 80 percent of their calories from the staple will have some slack in their food budget, and thus it will be theoretically possible for them to exhibit Giffen behavior, while those with staple calorie share chronically greater than 0.9 will likely be deprived of essential nutrients. ${ }^{\mathrm{A} 4}$

Finally, we must keep in mind that households in Gansu get part of their staple calories from noodles and other forms of wheat (approx. 7\% percent), which we do not count as part of "staple calories." Thus, an appropriate cut-off for Gansu may be more in the range of 0.7 than 0.8 .

Appendix Table. Staple Calorie Share of Minimum Cost Diet

\begin{tabular}{|c|c|c|c|c|c|c|c|c|c|c|}
\hline Scenario & A & $\mathrm{B}$ & $\mathrm{C}$ & $\mathrm{D}$ & $\mathrm{E}$ & $\mathrm{F}$ & G & $\mathrm{H}$ & $\mathrm{I}$ & $\mathrm{J}$ \\
\hline Sex & M & M & M & $\mathrm{F}$ & $\mathrm{F}$ & $\mathrm{F}$ & M & $\mathrm{F}$ & M & $\mathrm{F}$ \\
\hline Age & 25 & 35 & 75 & 35 & 85 & 22 & 40 & 40 & 40 & 40 \\
\hline Height (feet) & 6'2" & $5^{\prime} 9^{\prime \prime}$ & $5^{\prime} 4 "$ & $5^{\prime} 8^{\prime \prime}$ & $5^{\prime \prime \prime}$ & $5^{\prime} 4$ & $5^{\prime} 7^{\prime \prime}$ & $5^{\prime \prime \prime}$ & $5 ' 7 "$ & $5^{\prime} 2^{\prime \prime}$ \\
\hline Height (m) & 1.88 & 1.75 & 1.63 & 1.73 & 1.57 & 1.63 & 1.70 & 1.57 & 1.70 & 1.57 \\
\hline Activity & $\mathrm{V}$ & $\mathrm{L}$ & $\mathrm{S}$ & $\mathrm{L}$ & $\mathrm{S}$ & $\mathrm{V}$ & A & A & A & A \\
\hline Weight (lbs.) & 220 & 180 & 120 & 140 & 110 & 130 & 121 & 104 & 141 & 121 \\
\hline Weight (kg) & 100 & 82 & 55 & 64 & 50 & 59 & 55 & 47 & 64 & 55 \\
\hline \multicolumn{11}{|l|}{ Nutrient Requirements } \\
\hline Calories & 4264 & 2812 & 1727 & 2223 & 1351 & 2717 & 2554 & 2070 & 2718 & 2174 \\
\hline Lysine (mg) & 3100 & 2536 & 1691 & 1973 & 1550 & 1832 & 1705 & 1465 & 1987 & 1698 \\
\hline \multicolumn{11}{|l|}{ Least-Cost Diet (Hunan) } \\
\hline Rice $(\mathrm{g})$ & 996 & 636 & 385 & 504 & 291 & 641 & 603 & 485 & 634 & 503 \\
\hline Bean Curd (g) & 123 & 208 & 162 & 156 & 185 & 41 & 35 & 50 & 81 & 93 \\
\hline Cooking Oil (g) & 19.1 & 12.6 & 7.7 & 10 & 6.1 & 12.2 & 11.4 & 9.3 & 12.2 & 9.7 \\
\hline Cost (yuan) & 2.91 & 2.17 & 1.40 & 1.70 & 1.21 & 1.78 & 1.67 & 1.39 & 1.86 & 1.54 \\
\hline Staple Calorie Share & 0.85 & 0.82 & 0.81 & 0.83 & 0.79 & 0.86 & 0.86 & 0.86 & 0.85 & 0.84 \\
\hline \multicolumn{11}{|l|}{ Least-Cost Diet (Gansu) } \\
\hline Wheat $(\mathrm{g})$ & 986 & 629 & 381 & 499 & 288 & 635 & 597 & 480 & 628 & 498 \\
\hline Bean Curd (g) & 198 & 256 & 191 & 194 & 207 & 89 & 80 & 86 & 129 & 131 \\
\hline Cooking Oil (g) & 19.1 & 12.6 & 7.7 & 10 & 6.1 & 12.2 & 11.4 & 9.3 & 12.2 & 9.7 \\
\hline Cost (yuan) & 2.69 & 2.03 & 1.31 & 1.59 & 1.15 & 1.64 & 1.53 & 1.29 & 1.72 & 1.43 \\
\hline Staple Calorie Share & 0.84 & 0.81 & 0.80 & 0.82 & 0.78 & 0.85 & 0.85 & 0.84 & 0.84 & 0.83 \\
\hline
\end{tabular}

\footnotetext{
${ }^{\mathrm{A} 4}$ Nutritional sufficiency does not require consuming all essential amino acids at every meal. Thus even a consumer with a very high staple calorie share on the day of our survey may be nutritionally stable provided that they consumed more non-staples on other days.
} 


\section{APPENDIX III. CALCULATING VOUCHER USE TO EXAMINE POTENTIAL CASHING OUT}

An ideal measure of whether households had cashed out vouchers would compare, for each household, the total number of vouchers redeemed over the course of the intervention with the total amount of the staple consumed by the household and any increase in storage of the staple. However, this measure is simply not feasible since it would require continuously observing both variables for the whole period. ${ }^{51}$ Since our consumption data is based on only single-day observations on the survey dates, our estimate of total consumption over the subsidy period is imprecise. ${ }^{52}$ In addition, while we attempted to collect data on storage, response rates for the storage questions were very low because of respondents' difficulties in interpreting the questions. As a result, while these data can provide broad guidance in understanding the implementation of the intervention, the inherent imprecision associated with these measures is quite high. Nevertheless, for the sake of completeness we present approximate calculations.

Each household was issued vouchers sufficient to purchase $750 \mathrm{~g}$ of the staple per person per day. This corresponds to vouchers sufficient to purchase (on average) 2106 grams per day of rice for a typical household in Hunan. Overall, only $51 \%$ of vouchers that had been distributed as of the second survey had actually been redeemed by that time, meaning that the average household had redeemed the equivalent of 1078 grams per day. ${ }^{53}$ Estimated daily rice consumption for subsidized households during the subsidy period was 955 grams, implying a residual difference of 123 grams of rice per household per day, or $10 \%$ of the total number of vouchers redeemed before the second round of the intervention. However, as stated, it is likely that households used the subsidy to stock up on rice for later consumption. While our storage data are limited, we find that on average, household rice stores increased from 0.6 jin to 14.5 jin, ${ }^{54}$ which corresponds to redeeming an additional $74 \mathrm{~g}$ of vouchers per household per day, accounting for much of the discrepancy between rice consumed and vouchers redeemed. And

\footnotetext{
${ }^{51}$ Further, due to administrative difficulties in assigning and recovering individual identifiers from the vouchers, we unfortunately have only data on aggregate voucher usage to work with.

${ }^{52}$ And there is evidence of seasonality in consumption, especially for wheat in Gansu, with the control groups in each county displaying a decline in consumption between rounds 1 and 2 . Thus, in estimating the consumption of subsidy households during the subsidy period, we need to take into consideration that the round 2 consumption will be an underestimate of the consumption during a typical day of the subsidy period. To correct for this, we take the change in average consumption between rounds 1 and 2 for the control group in each county, assume a linear trend in consumption, and use this to adjust the round 2 consumption estimates for the treatment group.

${ }^{53}$ Overall, $76 \%$ of all vouchers issued were redeemed; as expected, there was a substantial increase in voucher redemption as the subsidy period drew to a close.

${ }^{54}$ Due to low response rates (19\% in round 2 ) we base this calculation only on households that responded to the storage question in both the first and second rounds of the survey.
} 
observations by our survey teams corroborate that households were, in fact, increasing storage during this time. Thus, as a rough approximation, only $3 \%{ }^{55}$ more vouchers were redeemed than were consumed or stored, ${ }^{56}$ suggesting that if there were any cashing out or re-selling, it was extremely limited. ${ }^{57}$

In Gansu, a typical household received 1996 grams of vouchers per day, and only $46 \%$ of vouchers available before the second-round survey were redeemed before that survey. Average household wheat intake in the first two rounds of the survey was $747 \mathrm{~g}$, while approximately $942 \mathrm{~g}$ worth of vouchers per day were redeemed, for a difference of $195 \mathrm{~g}$ per household per day. There is also evidence of increased storage in Gansu, which accounts for approximately $72 \mathrm{~g}$ of additional voucher usage per day, leaving approximately 123g (about 1 cup) of voucher redemptions unaccounted for, and a net-of-storage excess voucher redemption rate of $11 \%{ }^{58}$

There are in particular two counties in Gansu that account for much of the discrepancy; Kongdong (35\% unaccounted for vouchers) and Anding (22\%). We discovered that the high rate of voucher redemptions in Anding was due to the implementation team departing from our protocol and explicitly advising households to purchase as much wheat as possible and store it in order to take advantage of the subsidy program. ${ }^{59}$ And the implementation team reports that households were, in fact, purchasing and storing a great deal of extra wheat in Anding (given the imperfections in our storage data, it would not be surprising if we did not measure this increase). We have been unable to uncover the reason for the high voucher redemption rate in Kongdong, although our ground personnel report high storage levels and little evidence of cashing out of vouchers. ${ }^{60}$ While we have no direct evidence of cheating in these counties and the high redemption rates were apparently due to increasing wheat storage, as an additional robustness

\footnotetext{
${ }^{55}$ While estimates at the county level are less precise, the only real outlier, with $217 \mathrm{~g}$ grams or $10 \%$ more vouchers redeemed than can be accounted for by consumption and storage is Pingjiang county. To the extent that we view this as an outlier, the results of table 4 are robust to removing this county.

${ }^{56}$ Further, there may be additional 'leakage' our survey doesn't capture, such as consumption by visitors to the household, or rice lost or wasted during the cooking process, which may further explain the remaining discrepancy.

${ }^{57}$ While it is possible that households cashed out vouchers and then inflated their reported rice consumption to hide what they had done, this type of sophisticated cheating would work against our finding Giffen behavior.

${ }^{58}$ It is likely that in Gansu leakage is somewhat higher than in Hunan since flour is frequently used incidentally in the cooking process (e.g., covering surfaces for kneading bread) in ways that may not appear in the intake data.

59 To the extent that this advice encourages households to reduce consumption expenditure today in order to purchase and store wheat, this might work against our finding of Giffen behavior since when households spend less on current consumption they tend to consume relatively more wheat.

${ }^{60} \mathrm{In}$ fact, both counties show large increases in reported wheat purchases between the first and second round of the survey (despite there being a $40 \%$ across-the-board decline in wheat consumption and all other counties reporting reduced purchases). Reported purchases match up well with voucher usage in Anding and Kongdong.
} 
check we estimated regression (1) for Gansu under two scenarios. The first excludes just Kongdong, for which we have no clear reason for the discrepancy. Doing so, the resulting elasticity estimate for the $0.4-0.6$ staple-calorie share group actually increases in both magnitude and statistical significance $(1.37(.67))$ relative to the results using all counties (1.06 (0.56)). Excluding both Anding and Kongdong, which reduces the sample size by $42 \%$, results in an elasticity estimate of 0.79 with a p-value of 0.27 . Thus, while the elasticity estimate remains positive, it is no longer statistically significant. ${ }^{61}$

\footnotetext{
${ }^{61}$ Running the main regression in equation (1) with interactions for whether the household was a treated household in Anding or Kongdong, we are unable to reject the null hypothesis that these counties are the same as the other Gansu counties. For this reason, we have not eliminated them from the regressions reported in tables 7 and 8.
} 